\title{
Observations of Nanocrystalline Cubic Boron Nitride Formed with Plasma Spraying
}

\author{
K Madhav Reddy ${ }^{\mathrm{a}}$, Chawon Hwang ${ }^{\mathrm{b}}$, Metin Ornek ${ }^{\mathrm{b}}$, Steven L. Miller ${ }^{\mathrm{c}}$, William E. Mayo ${ }^{\mathrm{c}}$, \\ Alan Burgess ${ }^{\mathrm{d}}$, Richard A. Haber ${ }^{\mathrm{b}}$, Kevin J Hemker ${ }^{\mathrm{a}^{*}}$ \\ ${ }^{a}$ Department of Mechanical Engineering, Johns Hopkins University, Baltimore, MD 21218, USA \\ ${ }^{b}$ Department of Materials Science and Engineering, Rutgers, The State University of New Jersey, \\ Piscataway, NJ 08854, USA \\ ${ }^{c} H \& M$ Analytical Services, Inc. 35 Hutchinson Rd, Allentown, NJ 08501, USA. \\ ${ }^{d}$ SprayWerx Technologies Inc, 486 Fairway Drive, North Vancouer, British Columbia, Canada \\ V7G $1 L 5$.
}

\section{Abstract}

Cubic boron nitride (c-BN) has superior hardness and strength as compared to other ceramics that are commonly used as abrasives and in cutting tool applications. Cubic BN powders are generally produced under high pressures, usually greater than $10 \mathrm{GPa}$. Here, we report on the synthesis of nanocrystalline c-BN from metastable precursors without high external pressures using a novel plasma spray processing technique. Transmission electron microscopy (TEM) and electron energy loss spectroscopy (EELS) measurements indicate that the initial metastable precursor particles are amorphous and comprised of boron, carbon, nitrogen and oxygen with weak interatomic bonding that may easily undergo phase transformations during plasma spraying. Postmortem X-ray diffraction and TEM analysis of plasma spray deposits reveal the formation of crystalline phases of $\mathrm{BN}$, and high-resolution TEM observations demonstrate that c$\mathrm{BN}$ can be induced during the plasma spray process with the addition of appropriate catalysts. These observations point to a novel pathway for facilitating the transition from a low-density amorphous state to the high-density cubic BN phase.

*Corresponding author: Emails hemker@jhu.edu 
Key words: Metastable Precursors, Plasma Spray, Transmission Electron Microscopy, Nanocrystalline, Boron Nitride

\section{Introduction}

Boron Nitride $(\mathrm{BN})$ exists in several polymorphic forms such as amorphous BN (a-BN), hexagonal BN (h-BN), turbostratic BN (t-BN), rhombohedral BN (r-BN), monoclinic BN (m$\mathrm{BN})$, orthorhombic $\mathrm{BN}(\mathrm{o}-\mathrm{BN})$, wurtzite $\mathrm{BN}(\mathrm{w}-\mathrm{BN})$ and cubic $\mathrm{BN}$ (c-BN) phases [1-3]. At ambient pressure, h-BN exists in a stable crystalline structure that can be transformed to low density $(\sim 2.2 \mathrm{~g} / \mathrm{cc})$ metastable phases namely t-BN, m-BN and r-BN at relatively low pressures of less than $2 \mathrm{GPa}$. In contrast, transition to higher density $(\sim 3.5 \mathrm{~g} / \mathrm{cc}) \mathrm{w}-\mathrm{BN}, \mathrm{o}-\mathrm{BN}$ and c-BN phases develops only at high temperatures and pressures above $10 \mathrm{GPa}$ and these phases have a rigid atomic packing structure [4-6]. Among them, c-BN is known to be the hardest, with a hardness only next to diamond, and has found use in the fields of protective coatings and hard facing applications [7,8]. Importantly, c-BN possesses high oxidation resistance and low chemical reactivity, and it is perhaps best known for cutting ferrous material and carbide-forming hard substances where diamond fails completely $[9,10]$. However, currently produced c-BN is synthesized from the initial graphitic h-BN precursor with a high temperature and high pressure (HTHP) process and has grain sizes that range from hundreds of nanometers to tens of micrometers $[2,4,8,11]$. Reducing the temperatures and pressures needed to synthesize c-BN would both economize the production of c-BN and allow for better microstructural control.

Previous efforts to minimize the threshold pressure for the transformation of h-BN to c-BN have employed a catalytic processing methodology [12-18]. The common catalyst-solvent materials that are used for the synthesis of c-BN are $\mathrm{Li}, \mathrm{Al}, \mathrm{Mg}, \mathrm{Ca}, \mathrm{Li} 3 \mathrm{~N}, \mathrm{LiF}, \mathrm{Mg}_{3} \mathrm{~N}_{2}, \mathrm{Ca}_{3} \mathrm{~N}_{2}$, 
$\mathrm{Ca}_{3} \mathrm{~B}_{2} \mathrm{~N}_{4}$ and $\mathrm{Mg}_{3} \mathrm{~B}_{2} \mathrm{~N}_{4}$ [13-15]. The catalyst-solvent method utilizes the eutectic reaction between $\mathrm{BN}$ and the catalyst to accelerate crystallization, which occurs at a much faster rate in the eutectic solution, allowing for a reduction of pressures to $\sim 6 \mathrm{GPa}$ for the c-BN phase formation [16]. Further, alloy catalyst addition, such as $\mathrm{Mg}-\mathrm{Al}, \mathrm{Fe}-\mathrm{Al}, \mathrm{Cu}-\mathrm{Sn}, \mathrm{Mg}-\mathrm{Sn}, \mathrm{Al}-\mathrm{Co}$, $\mathrm{Al}-\mathrm{Mn}, \mathrm{Al}-\mathrm{Cr}$, and $\mathrm{Al}-\mathrm{Ni}$, reduced the pressures to $\sim 5 \mathrm{GPa}$, suggesting that the presence of low melting temperature phases enhances the phase transformation of h-BN into c-BN [17-18].

Alternatively, metastable a-BN has been used as an initial precursor, which is found to reduce the activation energy barrier for the nucleation and growth due to low structural ordering, and allows the a-BN to be readily converted to c-BN at pressures higher than $6 \mathrm{GPa}$ without the addition of catalysts [19-21]. Singh et al. investigated magnesium boron nitride solvent as a catalyst in the presence of a-BN and were able to reduce the threshold pressure of crystallization for c-BN to $2.5 \mathrm{GPa}[22,23]$. To date, c-BN has not been synthesized below $2 \mathrm{GPa}$ with conventional processing methods [23].

The plasma spray process has proven to be a powerful technique to synthesize a variety of metal and ceramic nanocrystalline powders $[24,25]$. In contrast to conventional processing methods, plasma spraying utilizes a high temperature plasma stream in which injected material powders are rapidly softened and sometimes melted while being accelerated towards a substrate [26,27]. During this process, high velocity impact on the substrate may induce desirable structural transformations [28]. However, this process has not been well explored for synthesizing high pressure stable phases, or to develop an understanding of the phase transitions in ceramic materials $[29,30]$. 
Here we report on of the synthesis of nanocrystalline c-BN without applying external pressure. The nanocrystalline c-BN is prepared by a novel plasma spray technique involving initial metastable amorphous BNCO (a-BNCO) with boric acid $\left(\mathrm{H}_{3} \mathrm{BO}_{3}\right)$ and beta boron $(\beta-\mathrm{B})$ catalysts. The phase evolution of nanocrystalline c-BN is demonstrated using X-ray diffraction and high-resolution transmission electron microscopy (HRTEM) characterization.

\section{Experimental details}

\subsection{Synthesis of BNCO precursor}

An initial precursor of an a-BNCO compound was synthesized by heating a mixture of boric acid $\left(\mathrm{H}_{3} \mathrm{BO}_{3}\right.$, Borax, Optibor $\left.{ }^{\circledR}\right)$ and melamine $\left(\mathrm{C}_{3} \mathrm{H}_{6} \mathrm{~N}_{6}\right.$, DSM, MelaminebyDSM $\left.{ }^{\mathrm{TM}}\right)$ in 3:1 molar ratio at $200{ }^{\circ} \mathrm{C}$ in air for $2 \mathrm{~h}$ and $400{ }^{\circ} \mathrm{C}$ in $\mathrm{N}_{2}$ gas atmosphere $(2 \mathrm{~L} / \mathrm{min})$ for $3 \mathrm{~h}$. To prepare powders having good flowability suitable for a plasma spray process, first a slurry was prepared and then spray dried based on the process reported by V. K. Pujarie et al. US Patent 6645612 B2, 2003) [31]. In brief, a-BNCO powders were added in surfactant (alkoxy silane, Dow Corning, Z6040) $-\mathrm{H}_{2} \mathrm{O}$ solution and after mixing (ball milling for $1 \mathrm{~h}$ using $\mathrm{ZrO}_{2}$ balls and $\mathrm{HDPE}$ plastic jar) a binder- $\mathrm{H}_{2} \mathrm{O}$ solution ( $3 \mathrm{wt} \%$ PEG 400 in $\mathrm{DI} \mathrm{H}_{2} \mathrm{O}$ ) was added to the dispersion and then post ball-milling was conducted for 600 seconds. The solid content of slurry was $30 \mathrm{wt} \%$ and the amounts of surfactant and binder $-\mathrm{H}_{2} \mathrm{O}$ solution were designed to be $5 \mathrm{wt} \%$ of solid content and 9 $\mathrm{wt} \%$ of the initial dispersion, respectively. Spray drying of slurry thus prepared was carried out with a spray drier (BÜCHI, B-290) at conditions of $200{ }^{\circ} \mathrm{C}$ inlet temperature and $600 \mathrm{~L} / \mathrm{h}$ air

flow rate. Two compositions of powders were prepared for plasma spray process: i) a$\mathrm{BCNO}+\mathrm{H}_{3} \mathrm{BO}_{3}$ mixture (a-BCNO: $\mathrm{H}_{3} \mathrm{BO}_{3}=75: 25$ wt \%) and ii) a-BNCO$+\mathrm{H}_{3} \mathrm{BO}_{3}+\mathrm{B}$ (a-Boron, ABCR GmbH \& CO. KG, Grade 1-A) mixture (a-BNCO:H33 $\mathrm{BO}_{3}: \mathrm{B}=60: 20: 20 \mathrm{wt} \%$ ). 


\subsection{Processing of $\mathrm{BN}$ using a novel plasma spray technique}

Plasma spraying was carried out with a DC Axial type gun (SprayWerx Technologies Inc., Axial III) at the National Research Council Canada. The main operating conditions including plasma gas chemistry, applied current and power, stand-off-distance, and gas flow rate are summarized in Table 1. The particle temperature and particle velocity during the plasma spray process, which were measured using an Accuraspray system (Tecnar Automation, St-Bruno, QC). Powders were plasma-sprayed onto a water-cooled aluminum chill plate and then scraped off plate using a steel scrapper.

\subsection{Characterization}

All the samples prepared in this study, were characterized by X-ray diffraction (XRD), scanning electron microscopy (SEM), and transmission electron microscopy (TEM). The crystal structure and average crystallite size were evaluated using XRD. The SEM studies were done using a field emission SEM (ZEISS, SIGMA) to obtain the surface morphology of pre-and postprocessed samples. The pre- and post processed powders were dispersed in distilled water and then allowed to settle on carbon coated copper grids for investigation by TEM (Philips FEI CM300) equipped with a Gatan 200 electron energy loss spectroscopy (EELS) detector. The bright field TEM images were used to study the grain size and morphology, while selected area electron diffraction (SAED) was used to study the crystal structure and lattice spacings. The chemical composition and bonding was established by EELS of both pre- and post process powder samples. The fine grain size observed by TEM was estimated using image processing and analysis (UTHSCSA Image Tool). Image simulations were performed by using the Win HREM (HREM Research Inc.). For these multisilice simulations, a structural model of the cubic BN unit 
cell $\left(\mathrm{a}=\mathrm{b}=\mathrm{c}=3.615 \mathrm{~A}^{\mathrm{o}} ; \alpha=\beta=\gamma=90^{\circ}\right)$ was provided in an input file [32]. The imaging conditions used in simulation and experiments were as follows: the incident electron beam energy was 300 $\mathrm{keV}$, the spherical aberration coefficient (Cs) was $1.2 \mathrm{~mm}$, the defocus spread of the primary beam was $10 \mathrm{~nm}$, the beam convergence was $0.3 \mathrm{~nm}^{-1}$, thickness was $5 \mathrm{~nm}$ and defocus value was $+10 \mathrm{~nm}$.

\section{Results}

\subsection{Characterization of a-BNCO synthesized precursor}

Figure 1 shows the synthesized powders obtained from the initial precursors of $\mathrm{H}_{3} \mathrm{BO}_{3}$ and $\mathrm{C}_{3} \mathrm{H}_{6} \mathrm{~N}_{6}$ by heat treatment at a final temperature of $400^{\circ} \mathrm{C}$ for 3 hours in a pure $\mathrm{N}_{2}$ atmosphere. The XRD pattern of synthesized powders (Fig. 1a) exhibits broad peaks indicating an amorphous phase. The SEM images display irregular shaped agglomerate particles of as-synthesized powders in the range of few hundred $\mathrm{nm}$ to $40 \mu \mathrm{m}$ as shown in Fig 1b. Low magnification TEM images (e.g. Fig. 1c) show thin sheets of agglomerated irregular particles that produce a selected area diffraction pattern (inset) indicative of an amorphous sample. Representative high resolution TEM images (e.g. Fig. 1d) demonstrate that the localized region does not form a periodic atomic lattice, further indicating that the synthesized powders are completely amorphous. An EELS spectrum taken for a single particle (Fig. 1e) shows the K-edges of boron (B), carbon (C), nitrogen $(\mathrm{N})$ and oxygen $(\mathrm{O})$ indicating the presence of these elements in the starting chemical synthesized powders. The chemical bonding of each element can be deduced from the fine structure of the K-edges and as noted in Fig. 1e sigma $(\sigma)$ and pi $(\pi)$ bonds [33] associated with B were located at 191.6 and $198.7 \mathrm{eV}, \mathrm{C}$ at 285.0 and $296.0 \mathrm{eV}, \mathrm{N}$ at 398.0 and $407.0 \mathrm{eV}$, and $\mathrm{O}$ at 531.0 and $538.0 \mathrm{eV}$ respectively. The presence of significant $\pi$ bonding in an amorphous 
material is indicative of weak interatomic bonding with $\mathrm{SP}^{2}$ bonded clusters $[34,35]$. Quantitative analysis of the peaks in the EELS spectra allow for local composition measurements and the measured relative $\mathrm{B}, \mathrm{C}, \mathrm{N}$ compositions are reported in Fig. 1f, $\mathrm{O}$ is less than $5 \%$ in atomic content. The results indicate a large composition variation with less than 25 atomic $\%$ of boron.

\subsection{TEM characterization of $\mathrm{H}_{3} \mathrm{BO}_{3}$ and $\beta$-B catalysts}

In order to increase the boron content in the synthesized BNCO precursor, we have used two catalysts $\mathrm{H}_{3} \mathrm{BO}_{3}$ and beta boron $(\beta-\mathrm{B})$. TEM images of $\mathrm{H}_{3} \mathrm{BO}_{3}$ revealed a thin fibrous network (e.g. Fig. 2a) and a higher magnification view (inset) showed a layered structure. EELS spectra taken from the thin layered region displayed B-K and O-K near edge elements both exhibiting $\pi$ and $\sigma$ bonding at $191.6 \mathrm{eV}, 198.7 \mathrm{eV}$, and $538.0 \mathrm{eV}, 547.5 \mathrm{eV}$ peak positions indicating weak bonding between layers that do not have long range three dimensional order as shown in Fig. $2 b$ [36]. A representative TEM image of $\beta$-B (Fig. 2c) shows the amorphous structure in the fine particles, and the corresponding EELS spectra confirms the structure to be dominated by a single edge for elemental boron (B-K) [33] (Fig. 2(d)).

\subsection{Illustration of pre- and post- plasma spray deposition processes of BNCO materials}

To increase the flowability of a-BNCO particles with their catalysts during the plasma spraying process, a spray dried slurry method was adopted. The spray drying was done for both a-BNCO with a $\mathrm{H}_{3} \mathrm{BO}_{3}$ catalyst and for a-BNCO with both $\mathrm{H}_{3} \mathrm{BO}_{3}$ and $\beta$-B catalysts, and both were deposited using similar plasma spray conditions to determine the effect of these catalysts on the metastable a-BNCO precursor. A typical SEM image of spray-dried powders of a-BNCO with the $\mathrm{H}_{3} \mathrm{BO}_{3}$ and the $\beta$-B catalysts (Figure 3a) shows an agglomerated spherical morphology 
with diameters ranging from $2 \mu \mathrm{m}$ to $40 \mu \mathrm{m}$. A higher magnification SEM image of the hollow spherical morphology displays a loosely bonded microstructure (Figure 3b). The SEM energy dispersive spectroscopy (EDS) mapping analysis of the hollow spherical particle (Figure 3c) revealed a distribution of boron, carbon, nitrogen and oxygen elements (Figure $3 \mathrm{~d}$ to $3 \mathrm{~g}$ ), indicating the particle is a BNCO compound.

The schematic in Figure 4 illustrates the plasma spray process that was used to synthesize crystalline BN phases. The precursor powders were fed into a plasma spray gun, where the powders were heated to high temperatures in a $\mathrm{N}_{2}$ atmosphere. Measurements made using the Accuraspray system indicate that the particle temperature and velocity were about $4200 \mathrm{~K}$ and $500 \mathrm{~m} / \mathrm{s}$, but the fact that the pyrometer images a mixture of the plasma and particles could have influenced the temperature measurements (Table 2). The corresponding residence time of a particle in the plasma flame is about $50 \mu \mathrm{s}$. The powder materials deposited on the substrate as flattened layers and were subsequently scraped off of the substrate and collected for post processing investigations. The final conversion efficiency was determined to be about 5-10 wt.\% in the particles that were scrapped off of the substrate.

Figure 5 shows SEM images of plasma sprayed particles that were deposited on and then scraped off of the cooling substrate. The plasma sprayed BNCO particles shown in Figure 5a are larger (5-20 $\mu \mathrm{m}$ in size) and more dense than the hollow spherical powders that existed before plasma spraying (Fig. 3a), suggesting a structural transition during the plasma spray process. The higher magnification image in Figure 5b shows a dense plasma spray deposit with smooth surface morphology (Fig. 3b). Another area of the plasma spray BNCO deposit is shown in Figure $5 \mathrm{c}$ and provides the signature of a melted zone (white arrow), though the degree of melting was variable between particles. EDS scans (Fig. 5(d-g)) taken from the yellow box in 
Figure $5 \mathrm{c}$ revealed the melted region to be rich in $\mathrm{B}, \mathrm{N}$ and $\mathrm{O}$ and deficient in $\mathrm{C}$, indicating the possible formation of $\mathrm{BN}$ and boron oxide $\left(\mathrm{B}_{2} \mathrm{O}_{3}\right)$ phases during the plasma spray process.

\subsection{Influence of $\mathrm{H}_{3} \mathrm{BO}_{3}$ catalyst on plasma spraying of a-BNCO}

Figure 6 summarizes the characterization of the powder that was produced by plasma spraying BNCO with the $\mathrm{H}_{3} \mathrm{BO}_{3}$ catalyst precursor. An XRD pattern (Fig. 6a) of the sprayed product reveals the presence of $t-B N, \mathrm{~B}_{2} \mathrm{O}_{3}$ and unreacted $\mathrm{H}_{3} \mathrm{BO}_{3}$. Low magnification TEM images of a flake that was scraped off of the substrate show a thin irregular morphology of particles (Fig. 6b), and the SAED pattern taken from the region in Fig. 6b is quite sharp and has well-defined circular rings (Inset Fig. 6c) as compared to the diffused electron diffraction pattern obtained from the as-synthesized a-BNCO precursor (see in Fig. 1c), indicating the existence of crystalline phases. The peak positions extracted using circular average method match those of tBN and c-BN (Fig. 6c). The observed intensity peaks are associated with t-BN reflections for basal and prismatic planes, as well as c-BN planes reflections (Fig. 6c). A higher magnification TEM image of Fig. $6 \mathrm{~b}$ can be found in Fig. $6 \mathrm{~d}$, and it shows evidence of the stacking ordering of t-BN and the fine crystalline growth of c-BN in an amorphous BNCO material. The EELS spectrum taken from this region shows strong B-K and N-K edges at 191.6-198.7 eV and 398.0$423.5 \mathrm{eV}$ and a small intensity of C-K edge and O-K edge can also be found (Fig. 6e). Quantitative estimates (Fig. 6f) of the amounts of each element in the BNCO particles were

obtained from the size of the B-K, N-K and C-K peaks and point to equal amounts of boron and nitrogen and a carbon composition of less than 20 atomic $\%$, indicating that definitive chemical changes occurred during plasma spray process (see Fig. 1f).

\subsection{Influence of $\mathrm{H}_{3} \mathrm{BO}_{3}$ and $\beta$-B catalysts on plasma spraying of a-BNCO}


Figure 7 summarizes the characterization of the material produced by plasma spraying of the a-BNCO precursor with both the $\mathrm{H}_{3} \mathrm{BO}_{3}$ and the $\beta$-B catalysts. XRD patterns (Fig. 7a) exhibited crystalline peaks of $\beta-\mathrm{B}, \mathrm{t}-\mathrm{BN}$, c-BN and unreacted $\mathrm{H}_{3} \mathrm{BO}_{3}$ indicating significant structural changes associated with the addition of the catalysts. The widths of the XRD peaks suggest that the average size of the crystalline c-BN is about $8 \mathrm{~nm}$. A low magnification TEM image displays the irregular BNCO particles and within each particle evidence of grains with a spherical morphology can be seen (Fig. 7b). The SAED ring pattern from this region (Fig. 7c) confirms the polycrystalline nature of the particle and the measured lattice parameters indicate significant amounts of the $\mathrm{c}-\mathrm{BN}$ phase along with $\mathrm{t}-\mathrm{BN}$ and $\beta-\mathrm{B}$ phases. Increasing the magnification of the TEM image reveals a wide range of nanocrystalline grain sizes within the BNCO material, as shown in Fig. 7d. The volumetric fraction of c-BN grains, estimated using image analysis from multiple TEM images, ranges from 2.5 to $8 \%$ in the plasma sprayed material.

\subsection{TEM characterization of formed nanocrystalline c-BN with plasma spraying}

Figure 8 shows direct TEM observations of fine c-BN grains that were synthesized by plasma spraying a-BNCO in the presence of $\mathrm{H}_{3} \mathrm{BO}_{3}$ and $\beta$ - $\mathrm{B}$. The grain sizes measured in over 100 TEM images of c-BN particles ranged from 1 to $20 \mathrm{~nm}$ with an average size of $6 \pm 3 \mathrm{~nm}$. Fig. $8 \mathrm{~b}$ shows a high-resolution TEM image taken from the region in Fig. $7 \mathrm{~d}$ and provides direct evidence of a grain size of about $5 \mathrm{~nm}$ with the cubic crystal structure and lattice spacing $\left(\mathrm{d}_{\mathrm{hkl}}=0.21 \mathrm{~nm}\right)$ for $\mathrm{c}-\mathrm{BN}$. An even higher magnification image (Fig. 8c) reveals a perfect lattice image that matches the HRTEM image simulation (insert) produced using a structural model of c-BN along the [101] direction. The EELS spectra from this region evidenced only $\sigma$ bonding at $196.5 \mathrm{eV}$ for the B-K edge and $420.5 \mathrm{eV}$ for the N-K edge. The presence of only $\sigma$ bonding is 
further evidence of the c-BN phase and is a characteristic of $\mathrm{SP}^{3}$ bonded materials [33-34]. Fig. 9a is a low magnification TEM image of a carbon film containing numerous fine c-BN grains that were separated from other low-density phases (BNCO and t-BN) with ultrasonication (1200 s) and captured on a carbon film for TEM analysis. High resolution TEM images (Fig. 9b) confirm that these fine spherical grains have lattice spacing of about $0.21 \mathrm{~nm}$, as estimated using line intensity profiles (Inset Fig. 9b), and compare well with c-BN oriented along the $<110>$ zone axis.

Figure 10 provides a comparison of threshold pressures for the formation of c-BN using different initial crystalline and amorphous precursors with their catalysts $[1,4,12-23,37]$. The graphical plot clearly illustrates that the introduction of amorphous starting material seems a promising route to achieve c-BN at relatively low pressures as compared to high crystallinity in h-BN. In our work, we have observed formation of nanocrystalline c-BN at relatively low pressures as made possible by the incorporation of metastable precursors into plasma spray processing.

\section{Discussion}

The microstructural observations of nanocrystalline c-BN formation can be rationalized by considering the influence of four key parameters: the initial precursor, the catalysts, the chemical reactions and the rapid deposition that occurs during the plasma spray process.

The effect of using an amorphous BNCO precursor on the formation of c-BN during the plasma spray process was evaluated in this study and was found to significantly reduce the pressure required for the phase transformation. The precursor that was synthesized from $\mathrm{C}_{3} \mathrm{H}_{6} \mathrm{~N}_{6}$ and $\mathrm{H}_{3} \mathrm{BO}_{3}$ had an amorphous structure containing boron, carbon, nitrogen and a small amount 
of oxygen (BNCO) with no microscopically detectable crystallinity as shown in Fig. 1. Also, the BNCO precursor was found to have weak chemical bonding between the atoms, which is the result of pi bonds (Fig. 1e) that may easily melt and reduce the activation energy barrier for the formation of c-BN during the plasma spray process. In-situ high pressure / high temperature XRD observations by Lorenz et al. demonstrated that having an amorphous structure reduces the temperature and pressure $\left(1200^{\circ} \mathrm{C}\right.$ and $\left.7 \mathrm{GPa}\right)$ needed to transform a-BN to c-BN [38]. By comparison, the ordered t-BN to c-BN formation proceeds through an intermediate h-BN step at relatively higher temperature and pressure $\left(1450^{\circ} \mathrm{C}\right.$ and $\left.8 \mathrm{GPa}\right)$ and is accompanied by a lower conversion rate from h-BN to c-BN $[19,38]$. These references coupled with our observations suggest that using metastable precursors with weak bonding and a high number of structural imperfections facilitates the phase transition to c-BN thus reducing the required processing pressures and temperatures to those accessible by plasma spray processing.

The addition of $\mathrm{H}_{3} \mathrm{BO}_{3}$ and $\beta$ - $\mathrm{B}$ catalysts to the metastable $\mathrm{BNCO}$ precursor also played an important role in obtaining stoichiometric $\mathrm{BN}$ phases and enhancing $\mathrm{c}-\mathrm{BN}$ formation. On average the initial a-BNCO precursor was found to have approximately 15 at. $\%$ boron compared to $\sim 40$ at. $\%$ of each carbon and nitrogen (Fig. 1f). A key finding in the current study is the fact that we can increase the boron content by adding $\mathrm{H}_{3} \mathrm{BO}_{3}$ and $\beta$-B catalysts to the precursor powders (Fig. 6e). We found that plasma spraying a-BNCO particles with only the $\mathrm{H}_{3} \mathrm{BO}_{3}$ catalyst induced a phase transition, which formed a stoichiometric t-BN and a small fraction of c$\mathrm{BN}$ phase (Fig. 6a, c). The addition of both $\mathrm{H}_{3} \mathrm{BO}_{3}$ and $\beta-\mathrm{B}$ to a-BNCO during plasma spraying resulted in a significant yield of nanocrystalline c-BN (Fig. 7 and 8). We speculate that the catalysts increase the boron content and at the same time promoted softening and melting of the a-BNCO particles in a manner similar to that reported in the belt chamber experiments of Lorenz 
et al. [39]. Lorenz et al. attributed the rapid nucleation of c-BN in h-BN with a $\mathrm{Mg}_{3} \mathrm{~N}_{2}$ catalyst (at $1650^{\circ} \mathrm{C}$ and $\sim 6 \mathrm{GPa}$ ) to the melting the $\mathrm{h}-\mathrm{BN}$ and the formation of $\mathrm{c}-\mathrm{BN}$ upon solidification [39]. Their results indicate that the application of high temperatures and pressures in the presence of a catalyst can lead to extremely fast formation of very small c-BN grains. In this light, our results indicate that adding $\mathrm{H}_{3} \mathrm{BO}_{3}$ and $\beta-\mathrm{B}$ to a-BNCO enhanced melting and nucleation of c-BN phase during the high temperature plasma spray process.

The chemical reaction of a-BNCO particles with the $\mathrm{H}_{3} \mathrm{BO}_{3}$ and $\beta$-B catalysts that occurs during the plasma spray process can be estimated from the phases and compositions measured by post-processing XRD and TEM. The addition of $\mathrm{H}_{3} \mathrm{BO}_{3}$ and $\beta$ - $\mathrm{B}$ to a-BNCO powders leads to the formation of stoichiometric t-BN and c-BN nanograins without the presence of carbon and oxygen, as shown in Fig. 8 and Fig. 9. The microstructural analysis suggests that the BNCO material is melted during plasma spraying and that the local chemical composition changes to BN phases before deposition on a cooled substrate (Fig. 5). The average atomic composition of the precursor a-BNCO was measured to be $15 \%$ boron, $40 \%$ carbon, $40 \%$ nitrogen, and $5 \%$ by EELS. Thus, $B_{3} C_{8} N_{8} O_{1}$ can be taken as the effective stoichiometry of the a-BNCO particles. The chemical reaction that occurs during vapor phase reduction can be estimated using the starting compositions of the precursor and catalysts, the relative amount of each, and the gases that are present, and the resultant equation is similar to what Yoon et al. [40] and Choi et al. [41] previously suggested.

$$
\begin{aligned}
3\left(B_{3} C_{8} N_{8} O_{1}\right)_{s} & +4 H_{3} B_{3(s)}+24 B_{(s)}+N_{2(g)}+H_{2(g)}+8 O_{2(g)} \\
& \rightarrow 18 \mathrm{BN}_{(s)}+B_{3} C_{8} N_{8} O_{1(s)}+B_{2} O_{3(s)}+2 H_{3} B_{3(s)}+12 B_{(s)}+4 H_{2} O_{(g)} \\
& +3 \mathrm{CO}_{2(g)}+13 \mathrm{CO}_{(g)}(1)
\end{aligned}
$$


$\mathrm{XRD}$ and TEM observations of the plasma sprayed products point to the presence of $\mathrm{t}-\mathrm{BN}$ and $\mathrm{c}-$ $\mathrm{BN}$ in addition to unreacted $\mathrm{B}_{3} \mathrm{C}_{8} \mathrm{~N}_{8} \mathrm{O}_{1}, \mathrm{H}_{3} \mathrm{BO}_{3}$ and $\mathrm{B}$. Choi et al. reported that a- $\mathrm{BN}$ with $\mathrm{B}_{2} \mathrm{O}_{3}$ liquid easily crystallizes and transforms to c-BN around $4 \mathrm{GPa}$ [41]. Based on our experimental observations, we argue that the $\mathrm{BNCO}$ precursors melted during the plasma spray process and decomposed producing various gases resulting in a structural transformation into stoichiometric $\mathrm{BN}$.

Local impact pressures associated with deposition may have played a role in the formation of both t-BN and c-BN. The impact pressure can be estimated by assuming that a shock wave is generated when the molten particles impact the cooled substrate [44-46]. In the present case, the instantaneous Hugoniot pressure $P_{H}$ upon impact on the substrate is calculated from the Rankine Hugoniot equation [47]. For a simple shock wave in a material at rest

$$
P_{H}=\rho_{o} U_{s} U_{p}
$$

where $\rho_{o}$ the density, particle velocity $\left(U_{p}\right), U_{s}$ is the shock velocity, $\left(U_{p}\right)$ is the particle velocity. The shock velocity [48] can be written

$$
U_{s}=\mathrm{a}+\mathrm{bU}
$$

where $\mathrm{a}$ is the sound velocity, $\mathrm{b}$ is related to a Gruneisen parameter that can be expressed as

$$
b=0.5+\left(\frac{3 \alpha k}{2}\right) \rho_{o} C_{v}
$$

where $\alpha$ is the thermal expansion coefficient, $k$ is the bulk modulus; $C_{v}$ is the specific heat at constant volume. When the particle velocity is $515 \mathrm{~m} / \mathrm{s}$, the density is $\sim 2 \mathrm{~g} / \mathrm{cc}$, and the sound velocity in $\mathrm{N}_{2}$ plasma mixtures is in the range of 1000 to $1500 \mathrm{~m} / \mathrm{s}[49,50]$, the estimated pressure ranges between 1.0 to $1.5 \mathrm{GPa}$. Which is significantly lower than the typical pressures reported for the formation of c-BN. [1,4,12-23,37]. 
The local impact pressure may have assisted in the formation of c-BN but it is too low to be the critical cause of this transformation. Moreover, dissipation of the energy as heat, work hardening, or phase transformations would further lower the impact pressure and its influence on the formation of c-BN. Taken as a whole, our result suggests that the formation of c-BN occurs because of an interplay between multiple factors, including but not limited to the use of an amorphous precursor, the role of the two catalysts as well as the temperature and impact pressure associated with the plasma spray process.

\section{Summary and Conclusions}

In this work we have systemically studied $\mathrm{BN}$ phase evolution associated with plasma spraying and found that incorporating metastable catalysts with an amorphous BNCO precursor significantly lowered the threshold pressure for the formation of nanocrystalline c-BN. The

experimental evidence in support of this finding was qualitatively and quantitatively demonstrated with XRD and TEM characterization. The main results are summarized as follows

(a) TEM observations and EELS analysis of the initial precursor evidenced a amorphous BNCO that possessed significantly less boron ( $\sim 20$ atomic \%) than carbon and nitrogen. The addition of $\mathrm{H}_{3} \mathrm{BO}_{3}$ and $\mathrm{B}$ catalysts to the metastable a-BNCO precursor elevated the boron content, and spray drying resulted in the formation of flowable hollow spherical particles that were easy to plasma spray.

(b) Analysis of BNCO deposits in plasma-sprayed samples pointed to the decomposition of hydrates and carbides in the presence of a $\mathrm{N}_{2}$ atmosphere, which leads to melting and vaporization and promotes the formation of crystalline t-BN and c-BN. 
(c) Depositing the metastable a-BNCO precursor with the $\mathrm{H}_{3} \mathrm{BO}_{3}$ catalyst only resulted in the formation of a minority of crystalline BN. HRTEM observations and EELS compositional analysis revealed the presence of stoichiometric BN nanocrystals, mainly t-BN with small trace amounts of c-BN, embedded in a BNCO matrix.

(d) TEM observations of a plasma sprayed metastable a-BNCO precursor with both $\mathrm{H}_{3} \mathrm{BO}_{3}$ and $\beta$-B catalysts revealed significant nanocrystalline c-BN formation with an average crystal size of $6 \pm 3 \mathrm{~nm}$. HRTEM images of these nanocrystals match image simulations based on the c-BN crystal structure, and EELS spectra of the resultant material display only $\sigma$ bonding for both B-K and N-K edges, which also confirms that these crystals are c-BN.

\section{References}

[1] R. Haubner, M. Wilhelm, R. Weissenbacher, B. Lux, Boron nitrides-properties, synthesis and applications, structure and bonding, Springer-Verlag Berlin Heidelberg 102 (2002), 1-45.

[2] R. H. Wentorf Jr, Synthesis of the cubic form of boron nitride, J. Chem. Phys. 34 (1961) 809812.

[3] R. T. Paine, C. K. Narula. Synthetic routes of boron nitride, Chem. Rev. 90 (1990) 73-91.

[4] F. P. Bundy, R. H. Wentrof, JR. Direct Transformation of Hexagonal Boron Nitride to Denser Forms, J. Chem. Phys. 38 (1963) 1144-1149. 
[5] L. Xu, J. Zhan, J. Hu, Y. Bando, X. Yuan, T. Sekiguchi, M. Mitome, D. Golberg, High yield synthesis of rhombohedral boron nitride triangular nanoplates, Adv. Mater. 19 (2007) 21412144.

[6] J. Y. Huang, H. Yasuda, H. Mori. HRTEM and EELS studies on the amorphization of hexagonal boron nitride induced by ball milling, J. Am. Ceram. Soc. 83 (2000) 403-409.

[7] R. H. Wentorf, R. C. DeVries, F. P. Bundy, Sintered superhard materials, Science 208 (1980) 873-880.

[8] G. Liu, Z. Kou, X. Yan, L. Lei, F. Peng, Q. Wang, K. Wang, L. Li, Y. Li, Y. Wang, Y. Bi, Y. Leng, D. He, Submicron cubic boron nitride as hard as diamond, Appl. Phys. Lett. 106 (2015) 121901.

[9] S. Veprek, The search for novel superhard materials, J. Vaccum Sci. Tech. 17 (1999) 24012420.

[10] J. Angserd, F. Liu, H. O. Andéren, Nanostructure of a cubic BN cutting tool material, Int. J. Refract. Metals Hard Mater. 49 (2015) 283-287.

[11] O. Fukunaga. Science and technology in the recent development of boron nitride materials, J. Phys.: Condens. Matter 14 (2002) 10979-10982.

[12] S. Nakano, O. Fukunaga, New scope of high pressure-high temperature synthesis of cubic boron nitride, Diam. Relat. Mater. 2 (1993) 1409-1413.

[13] M. Kagamida, H. Kanda, M. Akaishi, A. Nukui, T. Osawa, S. Yamaoka, Crystal growth of cubic boron nitride $\mathrm{Li}_{3} \mathrm{BN}_{2}$ solvent under high temperature and pressure, J. Cryst. Growth. 94 (1989) 261-269. 
[14] O. Fukanaga, S. Takeuchi, Nucleation of cubic boron nitride in the non-metallic and metallic solvents, J Phys: Conf. Ser. 215 (2010) 012138.

[15] M. M. Bindal, S. K. Singhal, B. P. Singh, R. K. Nayar, R. Chopra, A. Dhar, Synthesis of cubic boron nitride using magnesium as the catalyst. J. Cryst. Growth 112 (1991) 386-401.

[16] L. Vel, G. Demazeau, J. Etourneau, Cubic boron nitride: Synthesis, physicochemical properties and applications, Mater. Sci. Engg B 10 (1991) 149-164.

[17] H. Saito and M. Ushio, Yogyo-Kyokaishi, 77 (1969) 151

[18] T. Kobayashi, K. Susa, S. Taniguchi, New catalysts for the high-pressure synthesis of cubic BN, Mater. Res. Bull, 10 (1975) 1231-1235.

[19] H Lorenz, I. Orgzall, Influence of the initial crystallinity on the high pressure-high temperature phase transition in boron nitride, Acta Mater. 52 (2004) 1909-1916.

[20] H. Sumiya, T. Iseki, A. Onodera, High pressure synthesis of cubic boron nitride from amorphous state, Mat. Res. Bull. 18 (1983) 1203-1207.

[21] S. K. Singhal, J. K. Park, Synthesis of cubic boron nitride from amorphous boron nitride containing oxide impurity using Mg-Al alloy catalyst solvent, J. Cryst. Growth 260 (2004) 217222.

[22] B. P. Singh, G. Nover, G. Will, High pressure phase transformations of cubic boron nitride from amorphous boron nitride using magnesium boron nitride as the catalyst, J. Cryst. Growth 152 (1995) 143-149. 
[23] B. P. Singh, V. L. Solozhenko, G. Will, On the low-pressure synthesis of cubic boron nitride, Diam. Relat Mater. 4 (1995) 1193-1195.

[24] J. Karthikeyan, C. C. Berndt, J. Tikkanen, S. Reddy, H. Herman, Plasma sprayed synthesis of nanomaterials powders and deposits, Mater. Sci. Engg A 238 (1997) 275-286.

[25] D. Goberman, Y. H. Sohn, L. Shaw, E. Jordan, M. Gell, Microstructure development of $\mathrm{Al}_{2} \mathrm{O}_{3}-13$ wt. $\% \mathrm{TiO}_{2}$ plasma sprayed derived from nanocrystalline powders, Acta Mater. 50 (2002) 1141-1152.

[26] P. Fauchais, Understanding plasma Spraying, J. Phys. D: Appl. Phys. 37 (2004) 86-108.

[27] A. Vardelle, C. Moreau, N. J. Themelis, C. Chazelas, A perspective on plasma spray technology, Plasma Chem. Plasma Process. 35 (2015) 491-509.

[28] S. Sampath and H. Herman, Rapid solidification and microstructure development during plasma spray deposition, J. Therm. Spray Techn. 5 (1996) 445-456.

[29] X. Zhou, V. Shukla, W. R. Cannon, B. H. Kear, Metastable phase formation in plasma sprayed $\mathrm{ZrO}_{2}\left(\mathrm{Y}_{2} \mathrm{O}_{3}\right)-\mathrm{Al}_{2} \mathrm{O}_{3}$, J. Am. Ceram. Soc. 86 (2003) 1415-1420.

[30] P. V. Ananthapadmanabhan, T. K. Thiyagarajan, K. P. Sree Kumar, N. Venkatramani. Formation of nano-sized alumina by in flight oxidation of aluminum powder in a thermal plasma reactor, Scripta Mater. 50 (2004) 143-147.

[31] V. K. Pujari, W. T. Collins, J. J. Kutsch, High solids hBN slurry, hBN paste, spherical hBN powder, and methods of making and using them, US 6645612 B2 (2003). 
[32] V. L. Solozhenko, V. V. Chernyshev, G. V. Fetisov, V. B. Rybakov, I. A. Petrusha, Structure analysis of the cubic boron nitride crystals, J. Phys. Chem. Solids 51 (1990) 10111012.

[33] C. C. Ahn, O. L. Krivanek, EELS atlas: a reference collection of electron energy loss spectra covering all stable elements. Warrendale, Pa: Gatan, Inc., (1983)

[34] Y. Meng, H. K .Mao, P. J. Eng, T. P. Trainor, M. Newville, M. Y. Hu, C. Kao, J. Shu, D. Hausermann, R. J. Hemley, The formation of $\mathrm{SP}^{3}$ bonding in compressed BN. Nature Mater. 3 (2004) 111-114.

[35] Z. W. Sieh, K. Cherrey, N. G. Chopra, X. Blase, Y. Miyamoto, A. Rubio, M. L. Cohen, S. G. Louie, A. Zettl, R. Gronsky, Synthesis of BxCyNz nanotubules, Phys. Rev B 51 (1995) 11229.

[36] Y. Li, R. S. Ruoff, R. P. H. Chang Boron acid nanotubes, nanotips, nanorods, microtubes and microtips, Chem. Mater. 15 (2003) 3276-3285.

[37] T. E. Mosuang, T. E. Lowther, Influence of defects on the hBN to cBN transformation, Phys Rev. B 66 (2002) 014112

[38] H. Lorenz, I. Orgzall, Insitu observation of the crystallization of amorphous nitride at high pressures and temperatures, Scripta Mater. 52 (2005) 537-540.

[39] H. Lorenz, B. Lorenz, U. kühne, C. Hohlfeld, The kinetics of cubic boron nitride formation in the system BN-Mg $\mathrm{N}_{2}$, J. Mater. Sci. 23, 3254-3257 (1988).

[40] S. J. Yoon, A. Jha, Vapour phase reduction and the synthesis of boron-based ceramic phases, J. Mater. Sci. 30 (1995) 607-614. 
[41] J. Y. Choi, S. J. Kang, O. Fukunaga, J. K. Park, K. Y. Eun, Effect of $\mathrm{B}_{2} \mathrm{O}_{3}$ and hBN crystallinity on cBN synthesis, J. Am. Ceram. Soc. 76 (1993) 2525-2528.

[42] A. V. Kurdyumov, V. F. Britun, I. A. Petrusha, Structural mechanisms of rhombohedral BN transformations into diamond like phases, Diam. Relat. Mater. 5 (1996) 1229-1235.

[43] V. F. Britun, A. V. Kurdyumov, Mechanisms of martensitic transformations in boron nitride and conditions of their development, High Press. Res. 17 (2000) 101-111.

[44] R. Goswami, S. Sampath, H. Herman, Shock synthesis of nanocrystalline Si by thermal sparying, J. Mater. Res. 14 (1999) 3489-3492.

[45] R. Goswami, H. Herman, S. Sampath, J. B. Parise, Diamond synthesis by high velocity thermal spray. The laboratory analogue of a meteorite impact, J. Mater. Res. 15 (2000) 25-28. [46] R. Goswami, H. Herman, S. Sampath, J. Parise, Y. Zhu, D. Welch, Shock induced transformation in hexagonal boron nitride by high velocity thermal spray, J. Am. Ceram. Soc. 85 (2002) 2437-2443.

[47] W. J. Nellis, Shock compression in ultrapressure research, Scripta Metall. 22 (1988) 121125.

[48] J. A. Zukas, T. Nicholas, H. F. Swift, L. B. Greszczuk, D. R. Curran, Impact Dynamics Johns Wiley and Sons, NY, 1982.

[49] B. Pateyron, M. F. Elchinger, G. Delluc, P. Fauchais, Sound velcoity in different reacting thermal plasma systems, Plasma Chem. Plasma P. 16 (1996) 39-57.

[50] G. V. Samsonov, Handbook of the physicochemical properties of the elements, Springer Science \& Business Media, 2012.

\section{Acknowledgments}


This research was supported by the Defense Advanced Research Projects Agency (DARPA; Extended Solids) and was accomplished under grant W31P4Q-13-1-001.

\section{Figures caption}

Figure 1. Phase analysis and structural characterization of the heat-treated Melamine and boric acid precursor powders. (a) X-ray diffraction (XRD) shows significant peak broadening suggestive of an amorphous phase. (b) A typical SEM image of precursor powders displaying a non-uniform surface morphology. (c) TEM bright-field (BF) and selected area electron diffraction (SAED) pattern of the as-deposited material with a halo ring pattern consistent with the presence of an amorphous phase. (d) High-resolution TEM image confirming a completely amorphous structure. (e) EELS spectra of the as-deposited material identifying the presence of $\pi$ and $\sigma$ bonds in the $\mathrm{K}$ edges for boron (B), carbon (C), nitrogen (N) and oxygen (O). (f) EELSbased measurements of atomic composition of the BNCO deposition, taken at a number of different regions and showing large compositional variations.

Figure 2. Microstrucure of $\mathrm{H}_{3} \mathrm{BO}_{3}$ and $\beta$ - $\mathrm{B}$ catalyst. (a) TEM images of $\mathrm{H}_{3} \mathrm{BO}_{3}$ shows the fibrous network structure. (b) EELS spectra taken from the same region shows $\pi$ and $\sigma$ bonding in both B-K and O-K edges. (b) TEM images of $\beta$-B shows the amorphous structure. (d) EELS spectra contains only the B-K edge with $\sigma$ chemical bonding.

Figure 3. (a) A representative SEM image of sprayed dried plasma spray powders of a-BNCO precursor, with the $\mathrm{H}_{3} \mathrm{BO}_{3}$ and $\beta$ - $\mathrm{B}$ catalysts, showing the hollow spherical morphology with a particle size range from few hundred $\mathrm{nm}$ to $40 \mu \mathrm{m}$. (b) A high magnification SEM image of a 
hollow spherical particle displays a loosely bonded microstructure. (c) Reference SEM image for the EDS maps (d-g) that were taken in the yellow box. The EDS maps (d-g) from the particle reveal the $\mathrm{B}, \mathrm{C}, \mathrm{N}$, and $\mathrm{O}$.

Figure 4. A schematic description of the plasma spray process employed. Sprayed dried particles are injected into a high temperature plasma flame, where they are melted, rapidly accelerated to a high velocity, and deposited on a cooled substrate.

Figure 5. (a) The SEM image of plasma sprayed BNCO particles that were scraped of off the substrate, which resulted in their irregular size and morphology. (b) A high magnification SEM image clearly reveals solid particles as compared to the spherical hollow particles that were observed before plasma spraying (Fig 3b). (c) The as-deposited material also shows signs of localized melting (white arrow). The EDS maps (d-g) reveal that the melted region (yellow box) is $\mathrm{B}, \mathrm{N}$, O-rich and C-poor, suggesting the possible formation of $\mathrm{BN}$ and $\mathrm{B}_{2} \mathrm{O}_{3}$ phases.

Figure 6. Plasma sprayed a-BNCO with the $\mathrm{H}_{3} \mathrm{BO}_{3}$ additive only. (a) XRD patterns evidence the presence of turbostratic $\mathrm{BN}(\mathrm{t}-\mathrm{BN})$ and a small amount of unreacted $\mathrm{H}_{3} \mathrm{BO}_{3}$. (b) A lowmagnification TEM image showing thin irregular BNCO powder particles. (c) A SAED diffraction pattern taken from this region indicating the existence of crystalline phases, the extracted profile intensity of the SAED reveals the presence of t-BN with a small fraction of cubic BN (c-BN), but no h-BN phase. (d) High-resolution TEM image confirming the presence of t-BN and c-BN grains embedded in a BNCO matrix. (e) An EELS spectra taken from the region in (d) and evidencing $\pi$ and $\sigma$ bonds associated with the B-K edge and N-K edge. The $\pi$ and $\sigma$ bonds associated with the $\mathrm{C}-\mathrm{K}$ edge and $\mathrm{O}-\mathrm{K}$ edge are significantly reduced as compared 
pre-processed a-BNCO particles (f) Quantitative assessment of the edges revealed equal compositions of $\mathrm{B}$ and $\mathrm{N}$ and a reduction in carbon content to less than 20 atomic $\%$ wt.

Figure 7. Plasma sprayed a-BNCO with both $\mathrm{H}_{3} \mathrm{BO}_{3}$ and $\mathrm{B}$ additives. (a) XRD analysis showing the presence of t-BN and c- $\mathrm{BN}$ in addition to unreacted $\mathrm{H}_{3} \mathrm{BO}_{3}$ and $\mathrm{B}$ catalysts. (b) A lowmagnification TEM images showing the presence of a high-density of fine crystallites within the BNCO deposited material. (c) A SAED pattern taken from the as-deposited materials and showing relatively sharp diffraction rings of uniform intensity, suggesting the presence of grains with random orientation. (d) A higher magnification TEM image reveals that the as-deposited BNCO material is composed of many nano-crystals.

Figure 8. Experimental and simulated images of c-BN. (a) Grain size estimates of over a hundred crystallites take from regions like the one highlighted in Fig. 7d. (b) A typical highresolution TEM image taken along $<110>$ orientation (as indicated by the FFT in the insert) and showing an embedded crystallite with a lattice spacing of $0.21 \mathrm{~nm}$, which is indicative of cubic BN. (c) A higher magnification experimental HRTEM image is compared with an image simulation (insert) that was produced using the crystal structure for c-BN, a thickness of $4 \mathrm{~nm}$, and defocus of $+10 \mathrm{~nm}$. The match corroborates the presence of $\mathrm{c}-\mathrm{BN}$ and the atomic positions of boron and nitrogen are shown in the inset image. (d) The EELS spectra of this nanoparticle reveals only $\sigma$-bonding for the B-K and the $\mathrm{N}-\mathrm{K}$ edges further confirming the presence of c-BN.

Figure 9. Observations of numerous ultra-fine c-BN crystallites. (a) Lower magnification TEM image showing finely dispersed c-BN particles in the plasma sprayed BNCO materials. (b) Magnified Fourier filtered TEM image of a single particle revealing a c-BN grain oriented along its $<110>$ zone axis. The insert displays a line intensity profile with a lattice spacing of $0.21 \mathrm{~nm}$. 
Figure 10. Graphical representation of published threshold pressures and approaches for the formation cubic $\mathrm{BN}$ from the different precursors with their catalysts [1, 4, 12-23, 37]. The present work shows relatively low pressure synthesis of c-BN with appropriate catalyst in a plasma sprayed process. 
Table 1. Plasma spraying parameters for a-BNCO+$+\mathrm{H}_{3} \mathrm{BO}_{3}$ and a-BCNO$+\mathrm{H}_{3} \mathrm{BO}_{3}+\mathrm{B}$ mixtures

\begin{tabular}{lll}
\hline Parameters & a-BNCO+H & a-BOC \\
\hline Plasma gas chemistry & $100 \% \mathrm{~N}_{2}$ & $90 \% \mathrm{~N}_{2}-10 \% \mathrm{H}_{2}$ \\
Nozzle size of gun (inch) & $1 / 2$ & $1 / 2$ \\
Current (A) & 100 & 100 \\
Power (kW) & 59 & 66 \\
Stand-off-distance (mm) & 75 & 75 \\
Total gas flow rate (slpm) & 200 & 200 \\
Carrier gas/flow rate (slpm) & $\mathrm{Ar} / 15$ & $\mathrm{Ar} / 15$ \\
\hline
\end{tabular}


Table 2. Particle temperature (T) and velocity (V) measured during plasma spray process, of which powder composition was a-BNCO+$+\mathrm{H}_{3} \mathrm{BO}_{3}+\mathrm{B}$ mixture. The subscript corresponds to the distance from the nozzle front of gun, at which particle temperature and velocity were measured*.

\begin{tabular}{cccccccccccc}
\hline $\begin{array}{c}\text { Run } \\
\text { No. }\end{array}$ & $\begin{array}{c}\text { Total gas } \\
\text { flow rate } \\
(\text { slpm) }\end{array}$ & \multicolumn{2}{c}{$\begin{array}{c}\text { Plasma gas } \\
\text { chemistry }\end{array}$} & $\begin{array}{c}\text { Power } \\
(\mathrm{kW})\end{array}$ & \multicolumn{2}{c}{ Particle temperature (T) and velocity (V) } \\
& & $\begin{array}{c}\mathrm{N}_{2} \\
(\%)\end{array}$ & $\begin{array}{c}\mathrm{H}_{2} \\
(\%)\end{array}$ & $\begin{array}{c}\mathrm{Ar} \\
(\%)\end{array}$ & & $\mathrm{T}_{50}$ & $\mathrm{~V}_{50}$ & $\mathrm{~T}_{75}$ & $\mathrm{~V}_{75}$ & $\mathrm{~T}_{100}$ & $\mathrm{~V}_{100}$ \\
& 200 & 10 & 0 & 90 & 27 & 3400 & 300 & 2850 & 278 & $\mathrm{ND}$ & $\mathrm{ND}$ \\
$1-2$ & 200 & 10 & 10 & 80 & 40 & 3870 & 400 & 3340 & 340 & $\mathrm{ND}$ & $\mathrm{ND}$ \\
$1-3$ & 200 & 100 & 0 & 0 & 59 & 4125 & 442 & 4241 & 438 & 4870 & 401 \\
$1-4$ & 200 & 90 & 10 & 0 & 66 & 3861 & 552 & 4230 & 515 & 4470 & 400 \\
\hline
\end{tabular}

* Footnote: Particle velocities were measured using cross-correlation analysis of images captured on sensors a known distance apart and have a reported standard deviation of 0.5\%. Temperatures were measured with a twin wavelength pyrometer that sees a mixture of plasma and particles and may not be an exact representation of particle temperature. 


\section{figure 1}

a

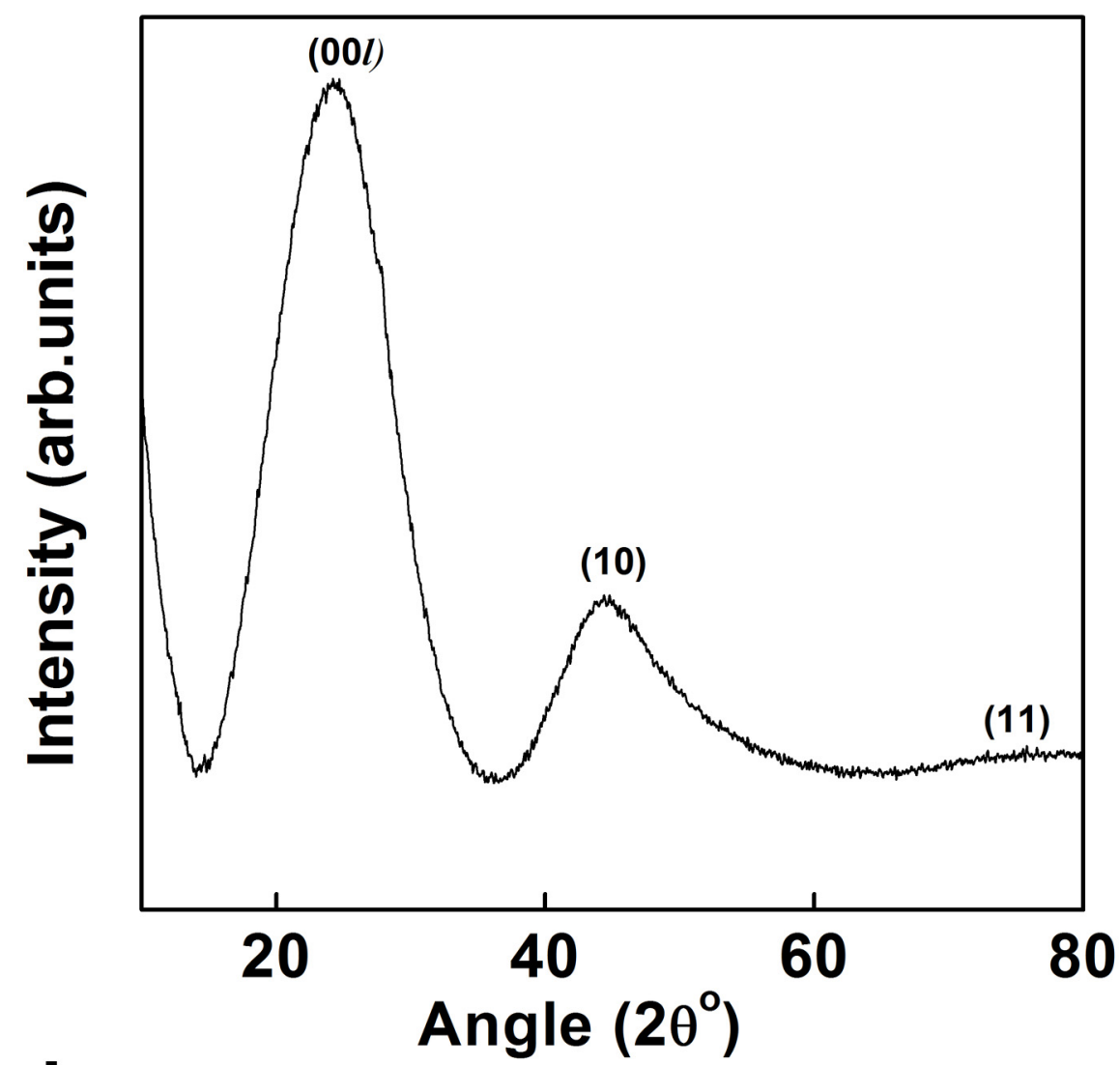

d

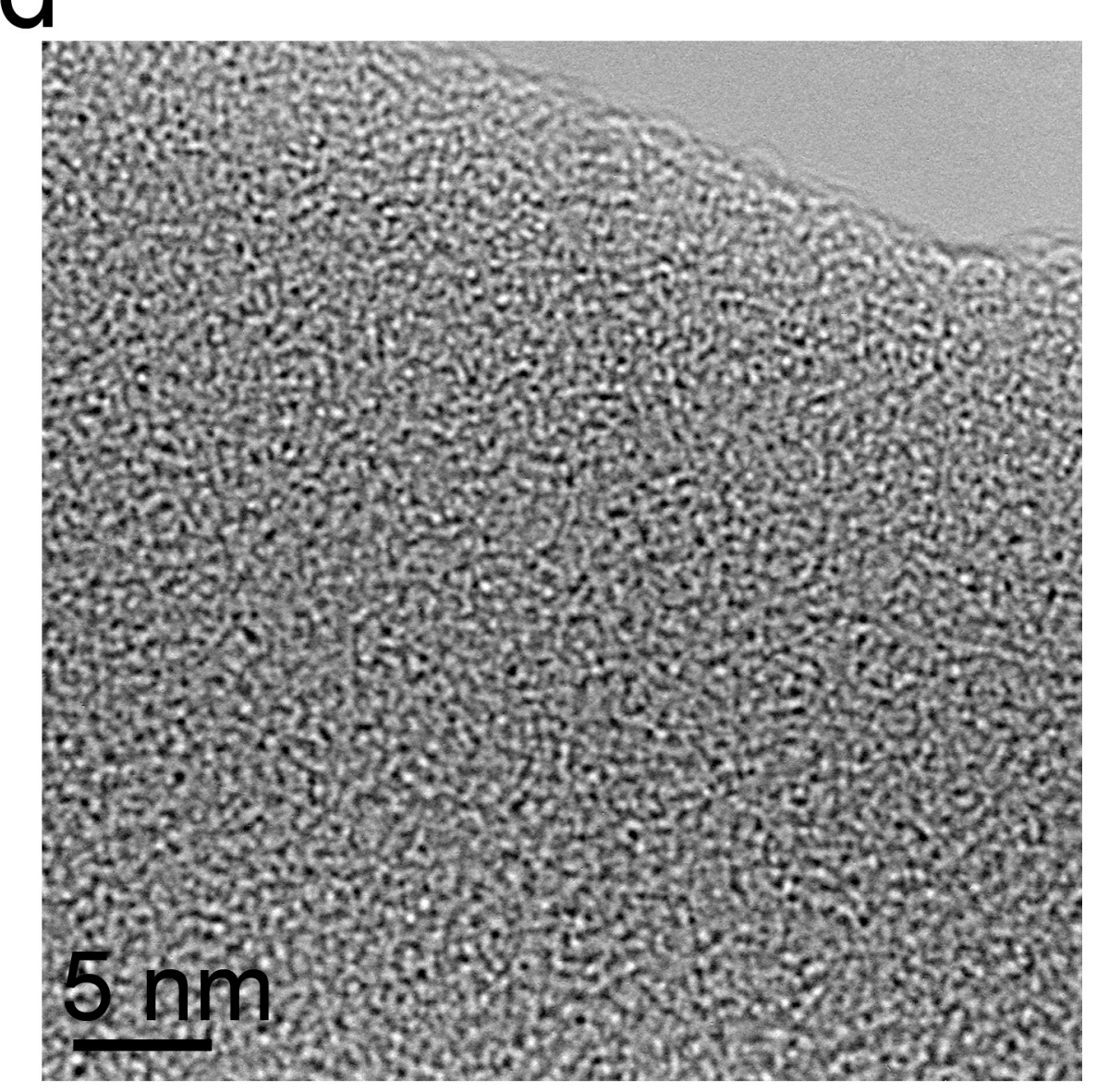

b

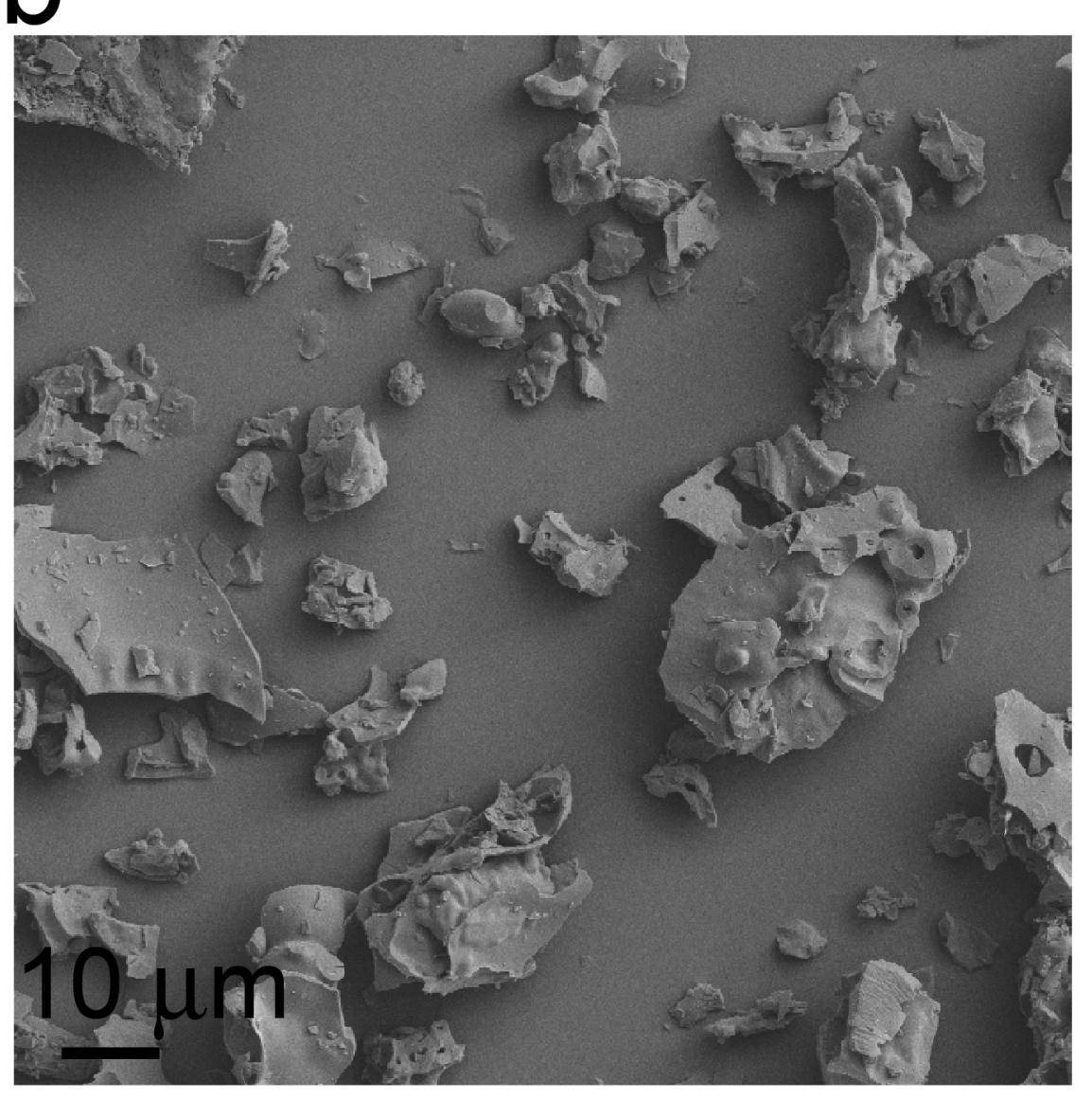

e

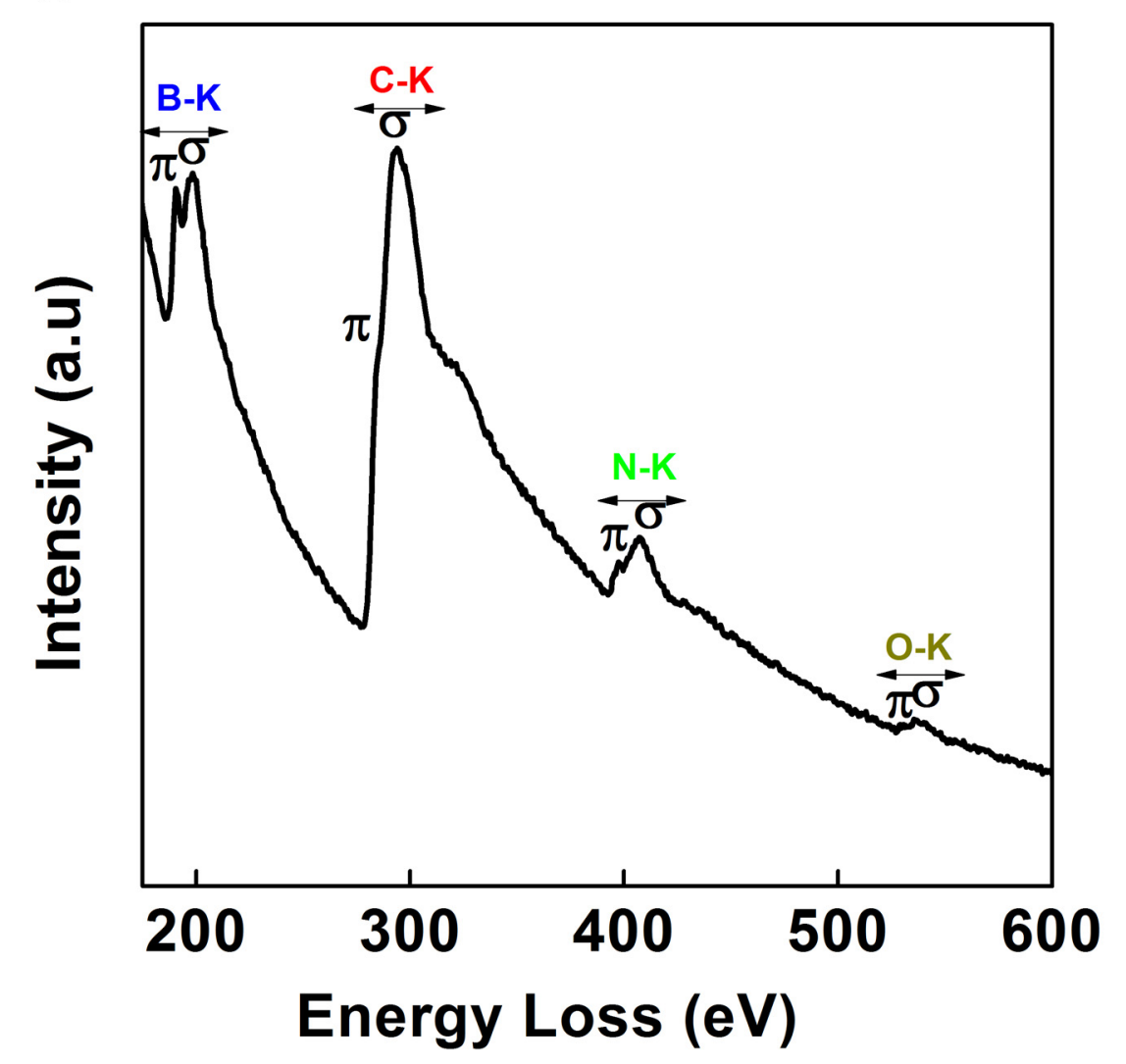

C

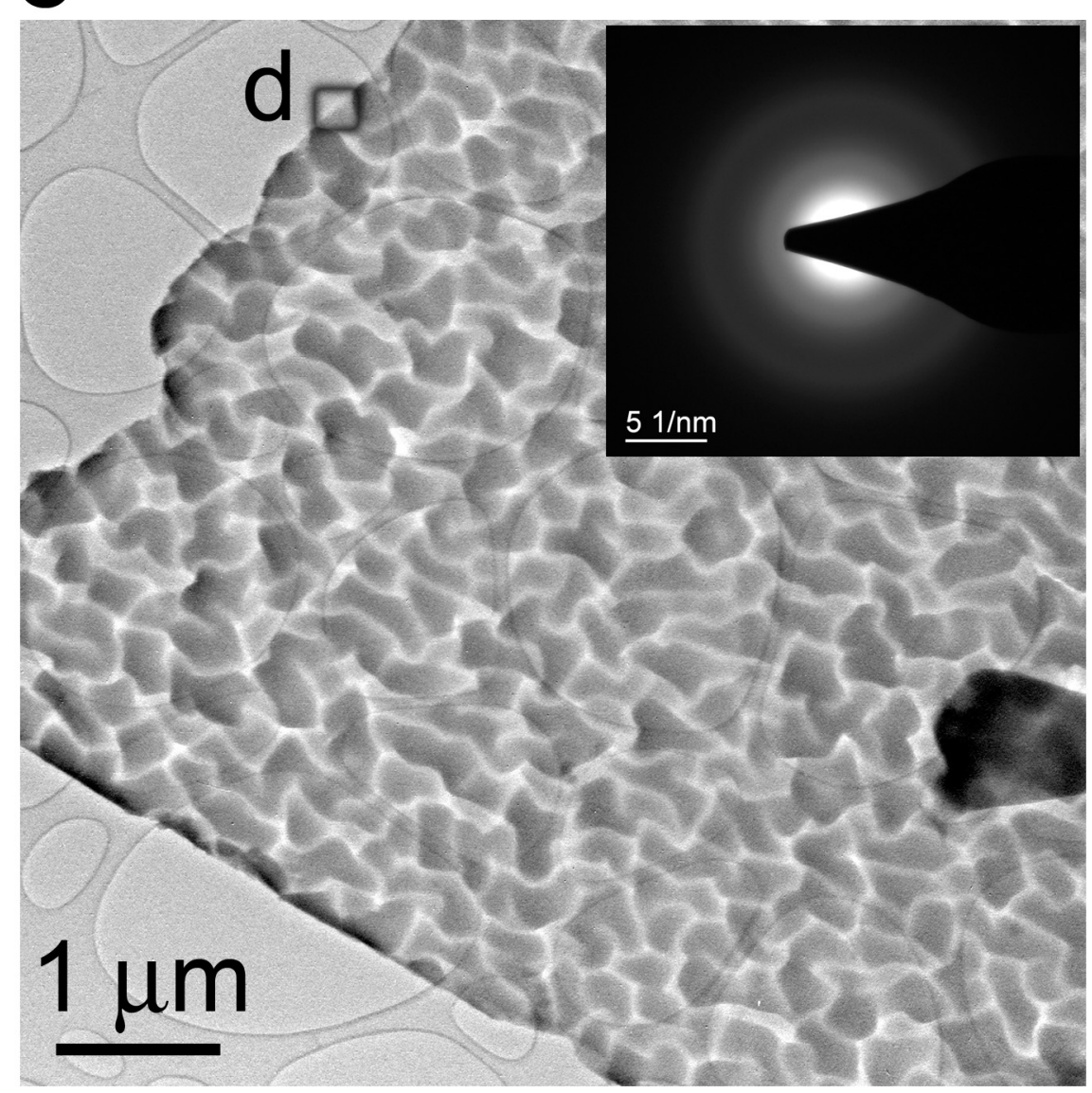

f

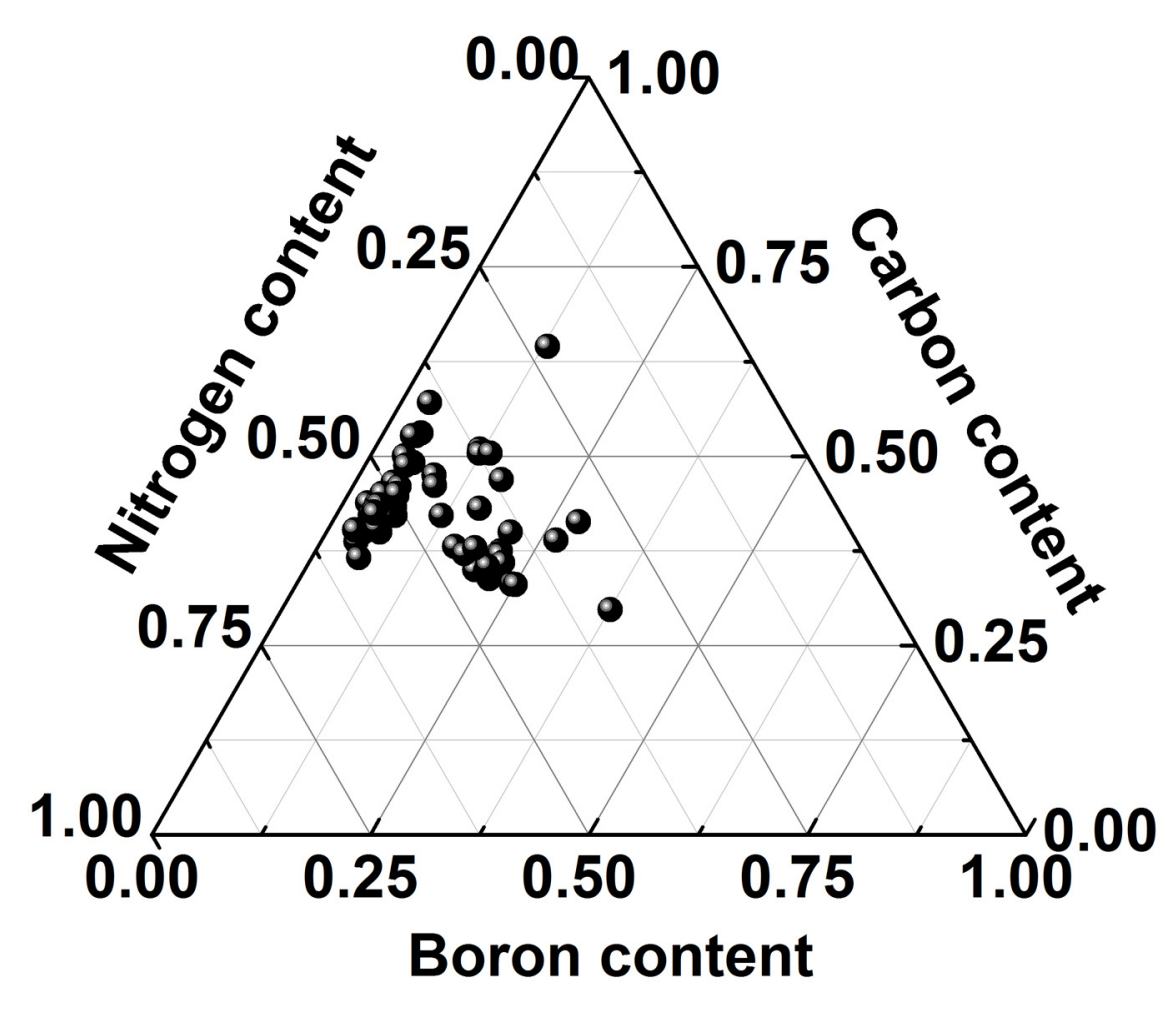



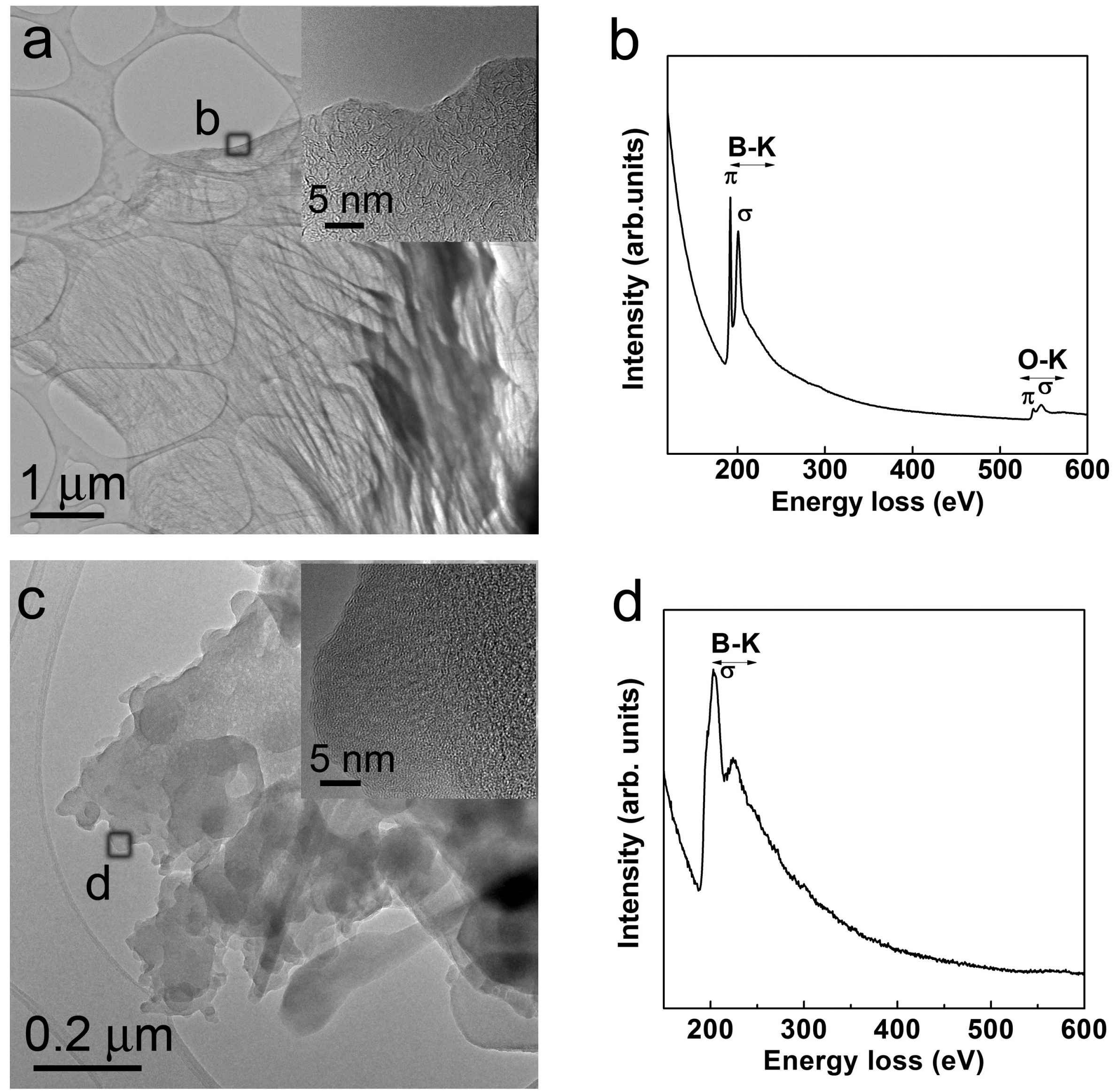

figure 2 
figure 3

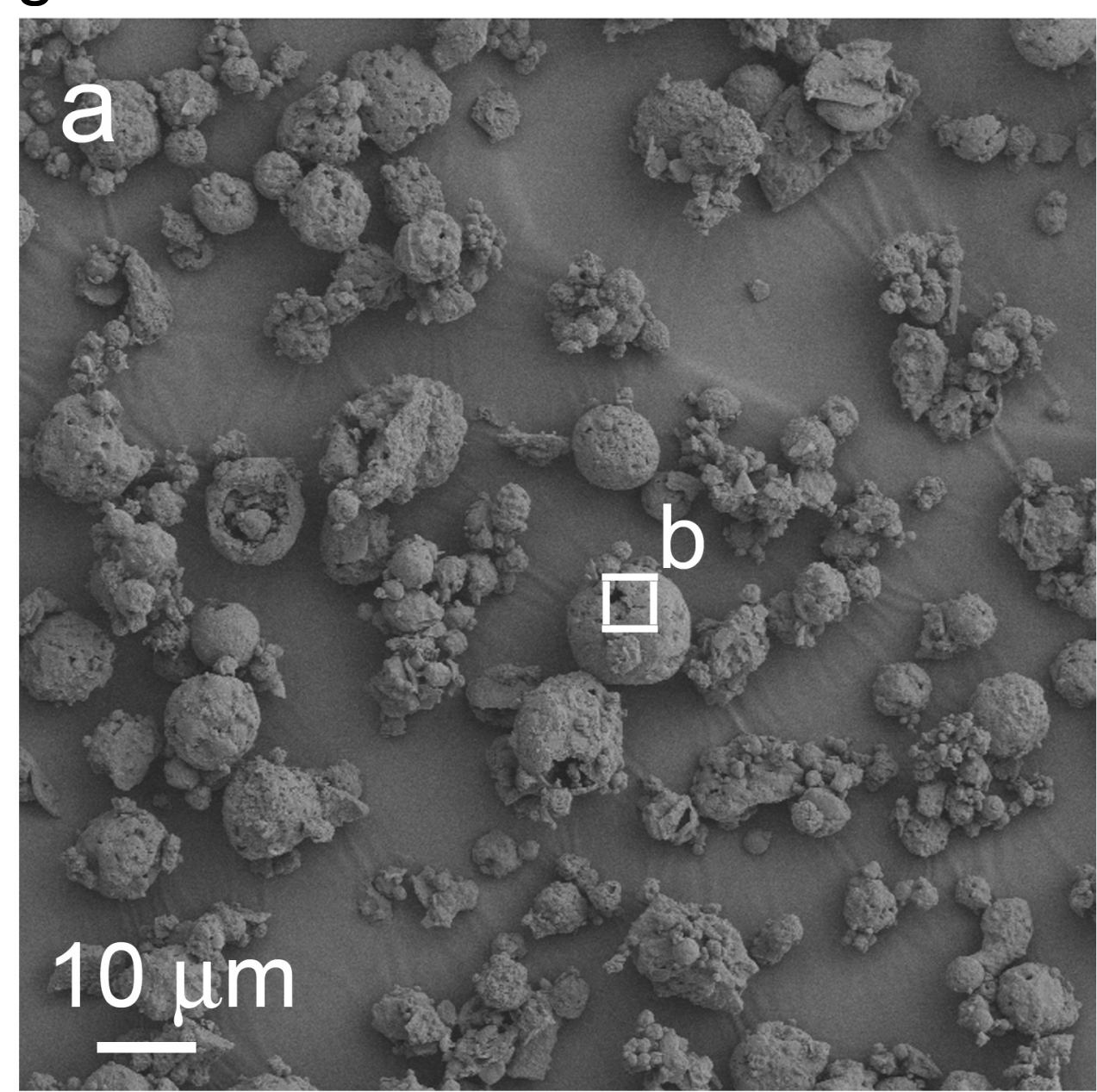

c

$10 \mu \mathrm{m}$

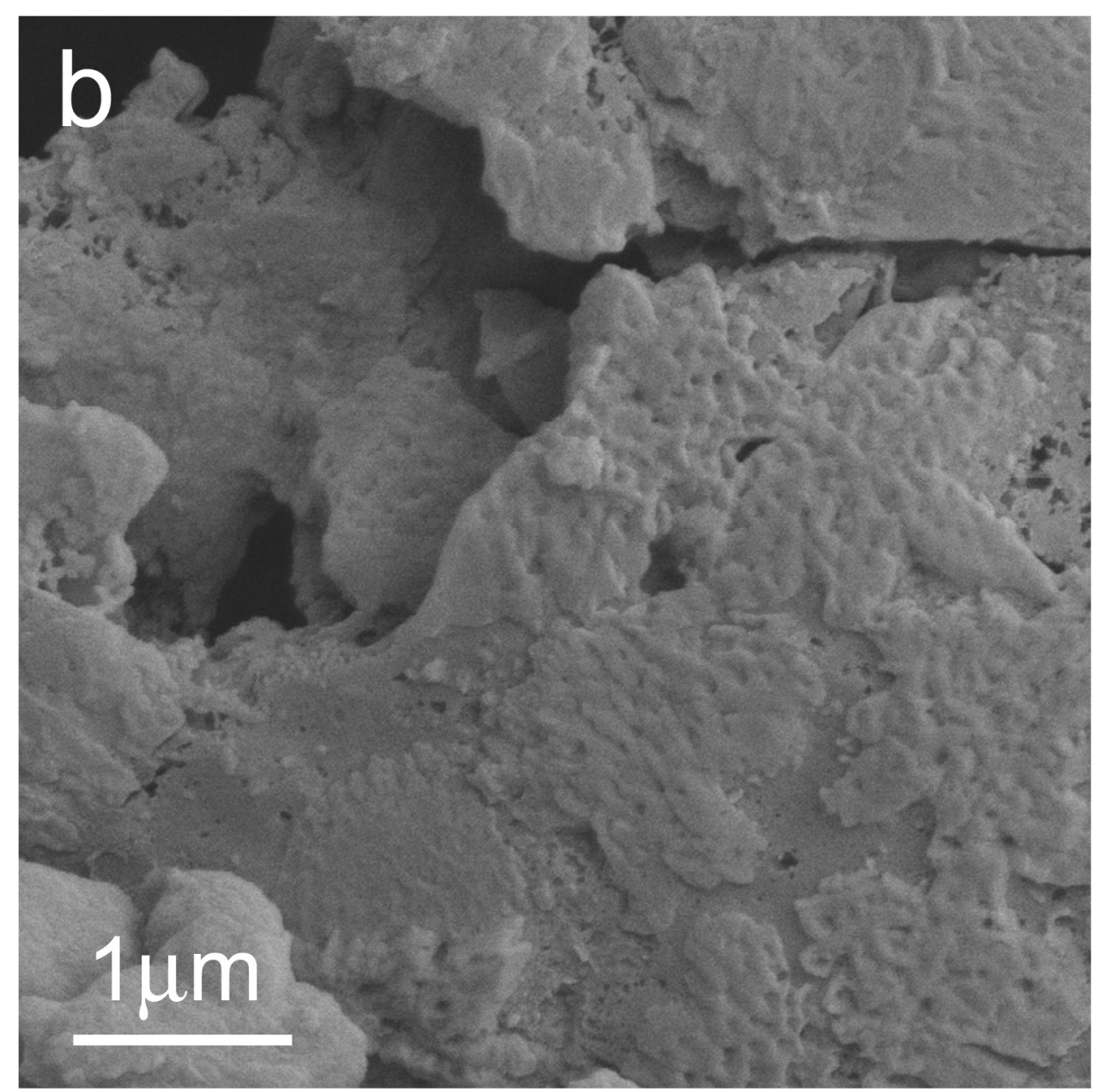

d

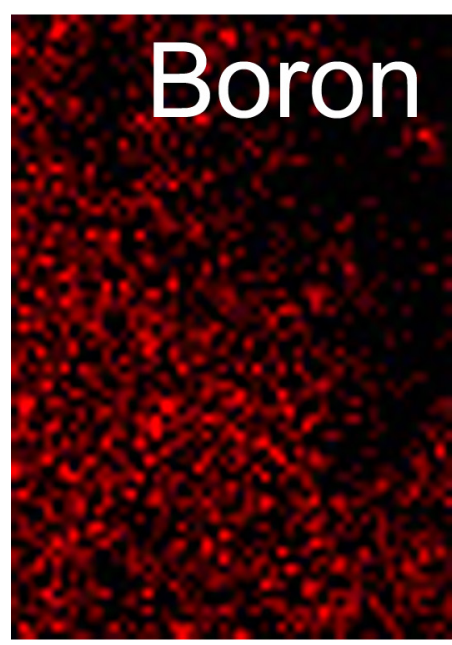

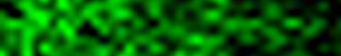

$f$ Carbon

g Oxygen.
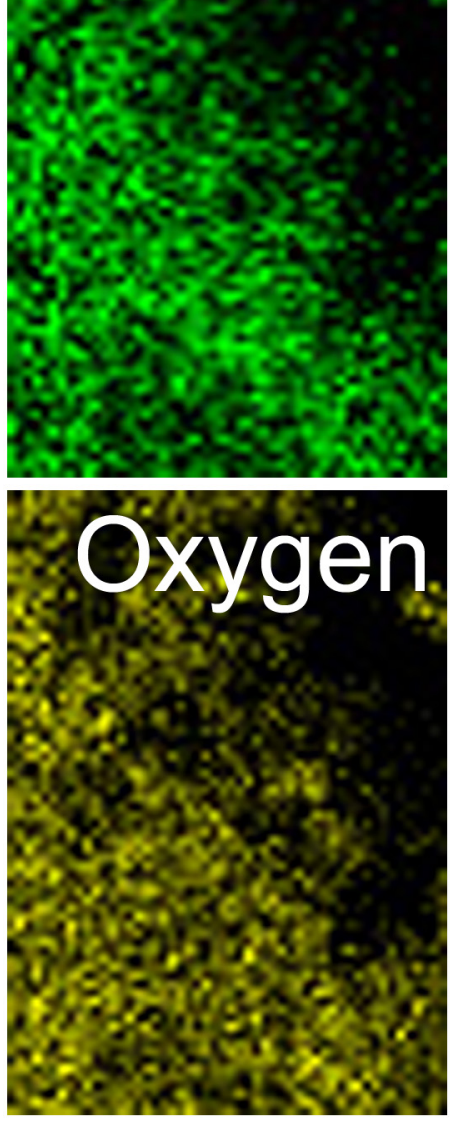

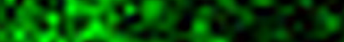

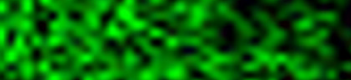

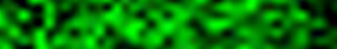

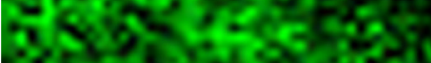

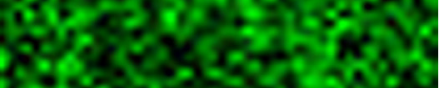

e Nitrogen

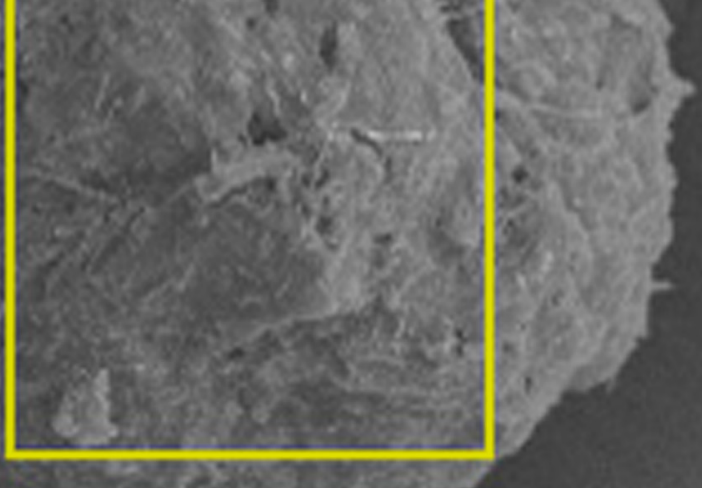

r 


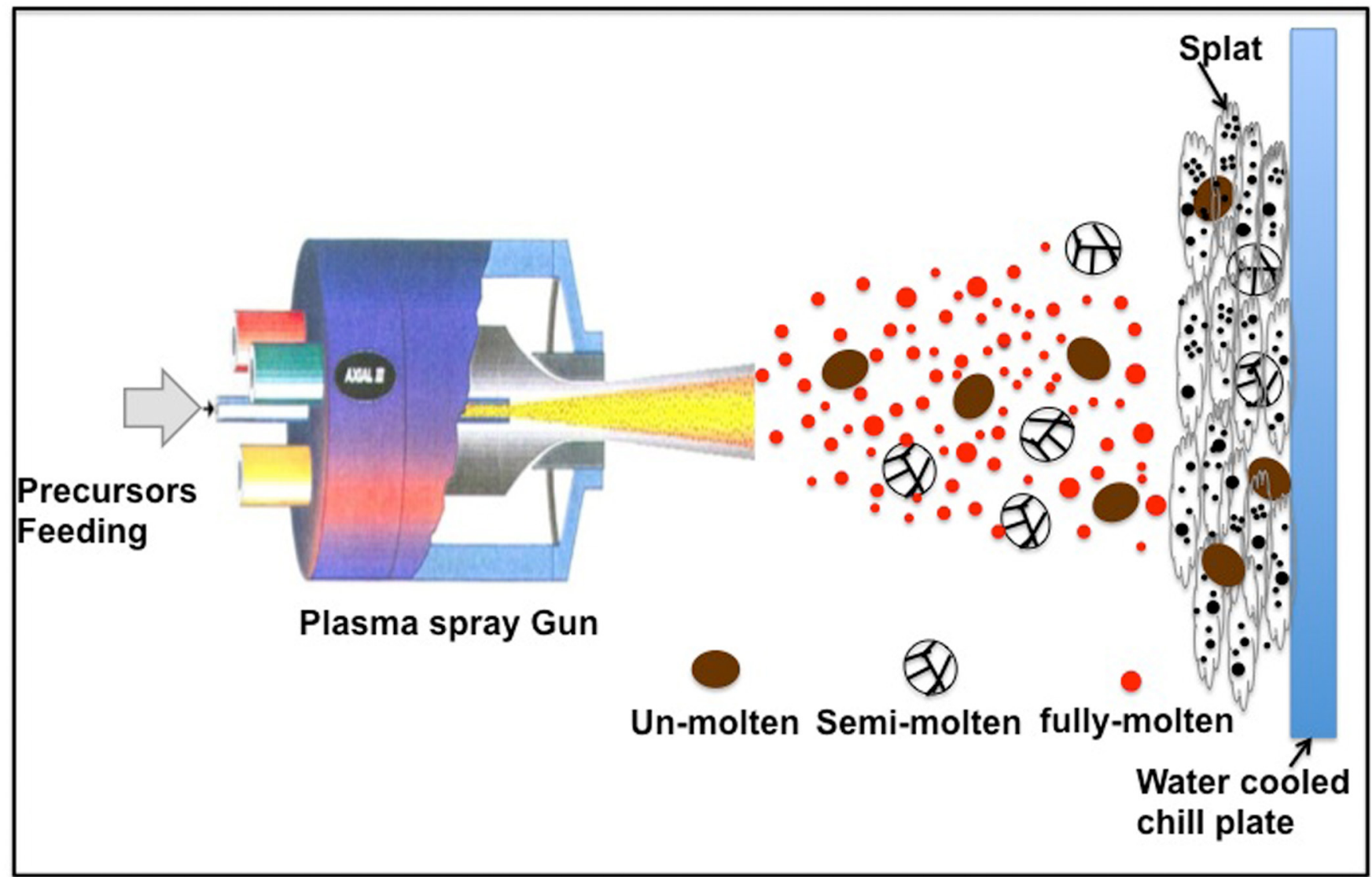



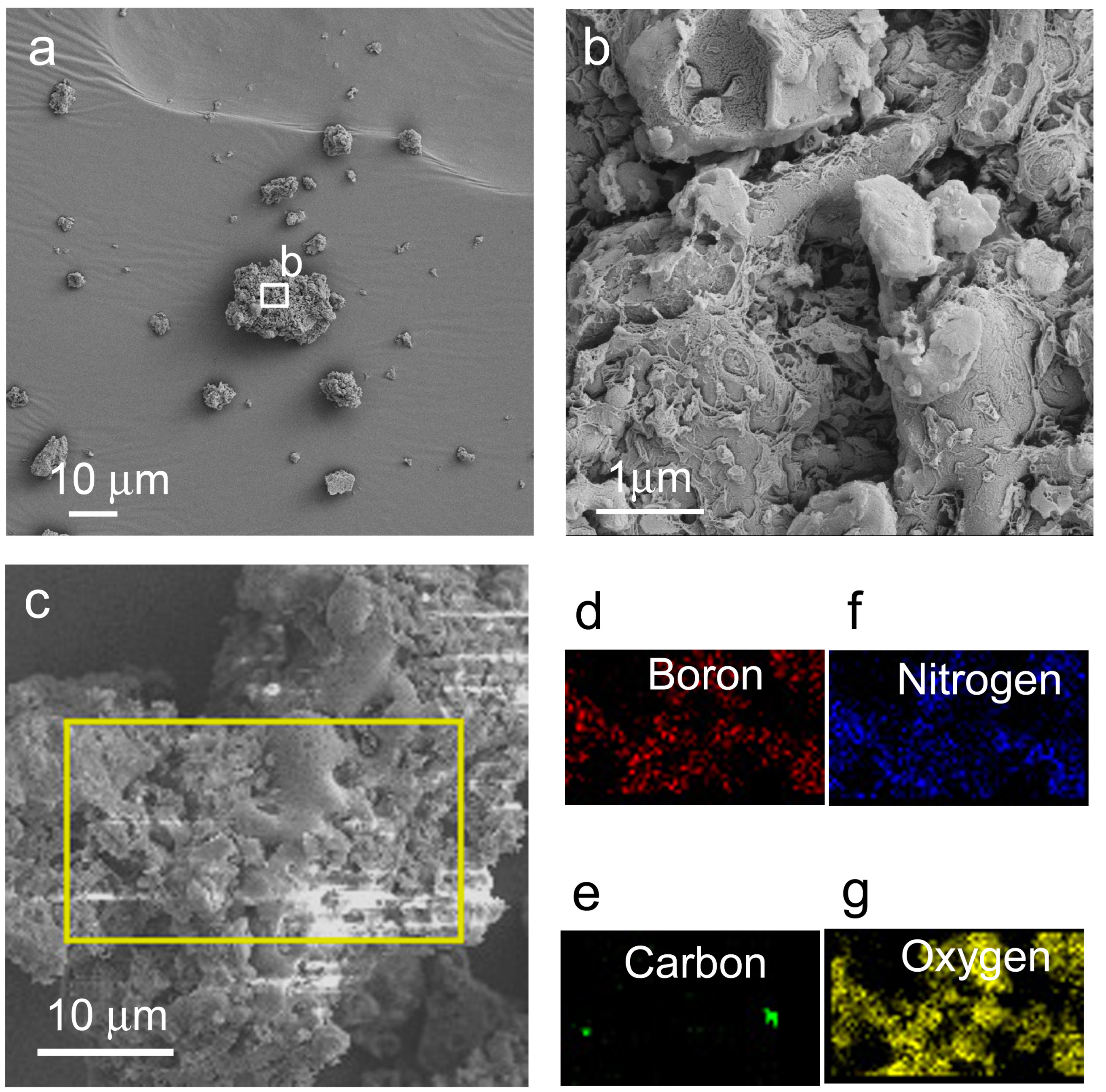
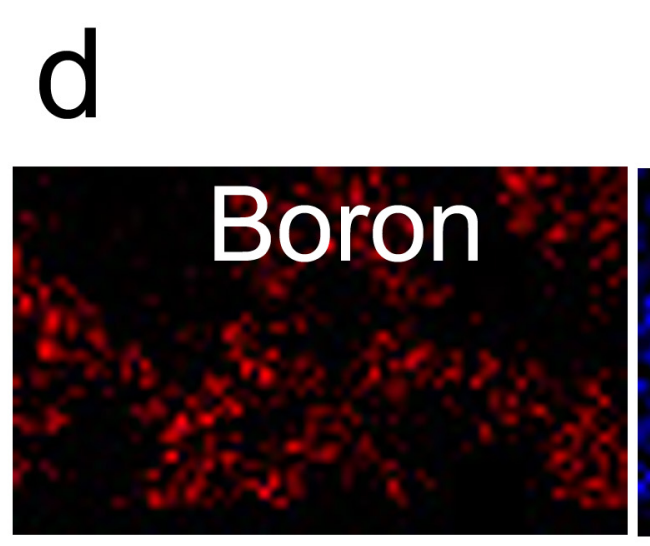

e

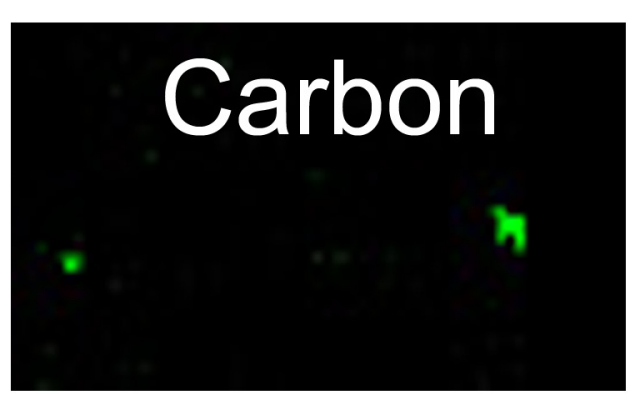

f

Nitrogen

figure 5 

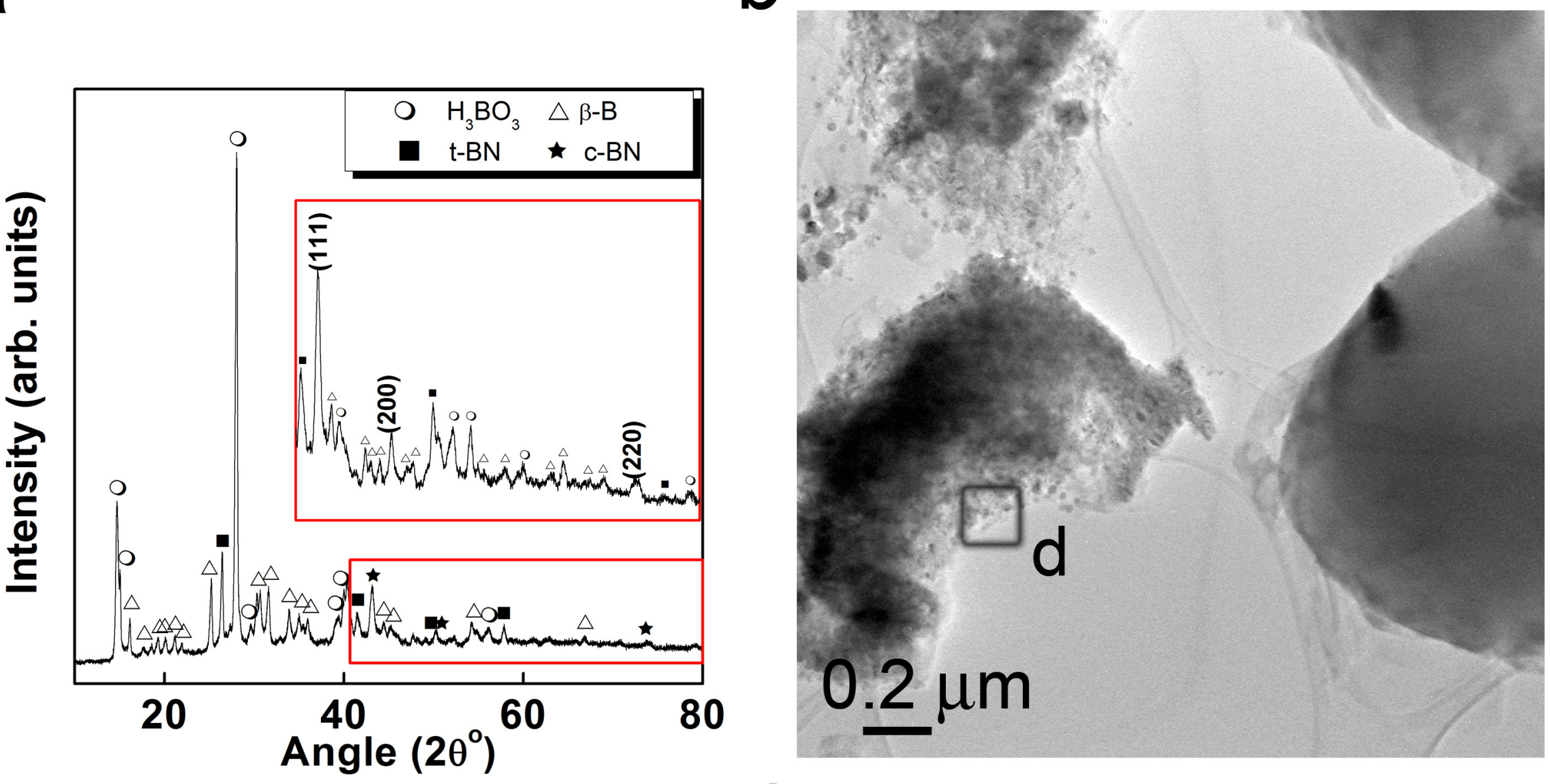

C

d
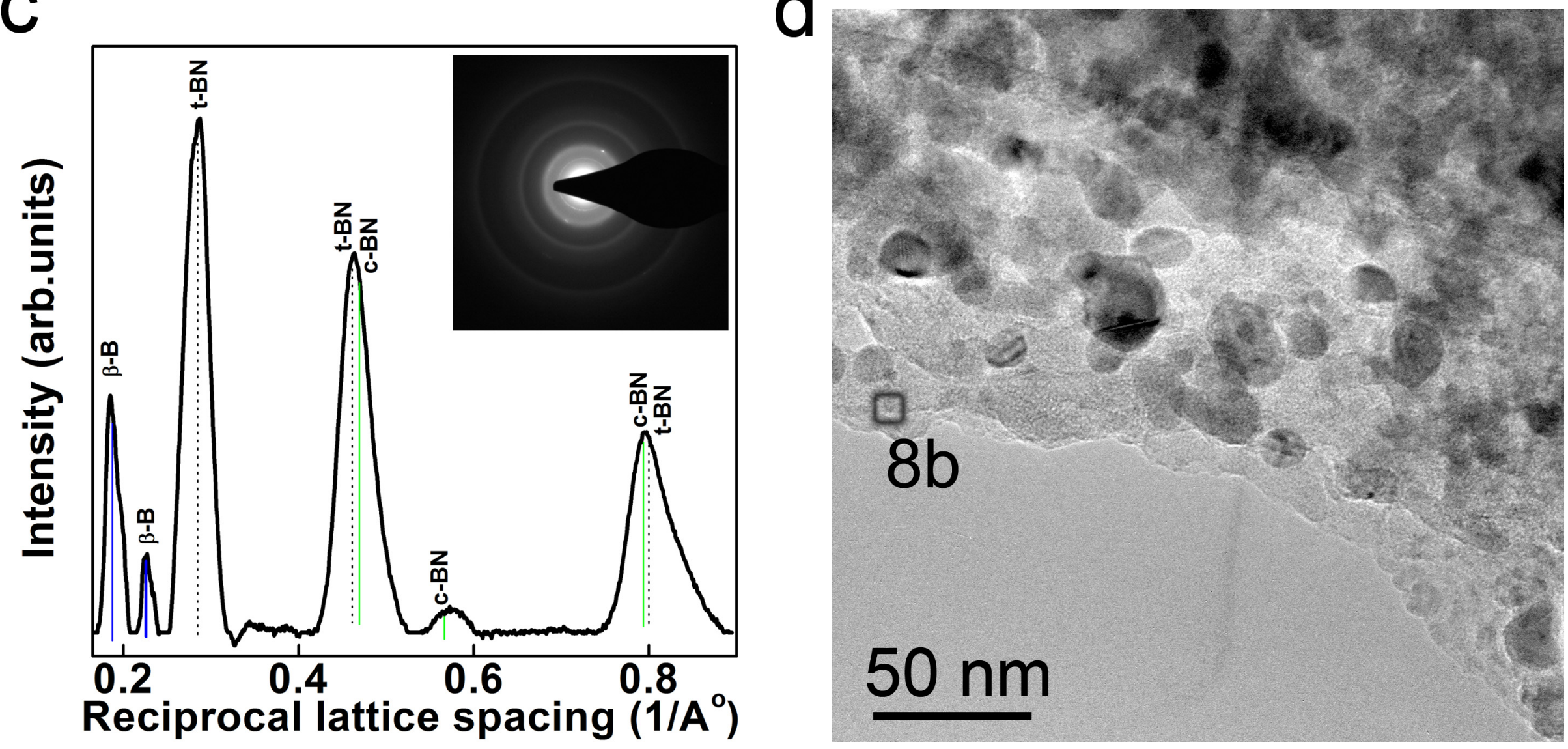


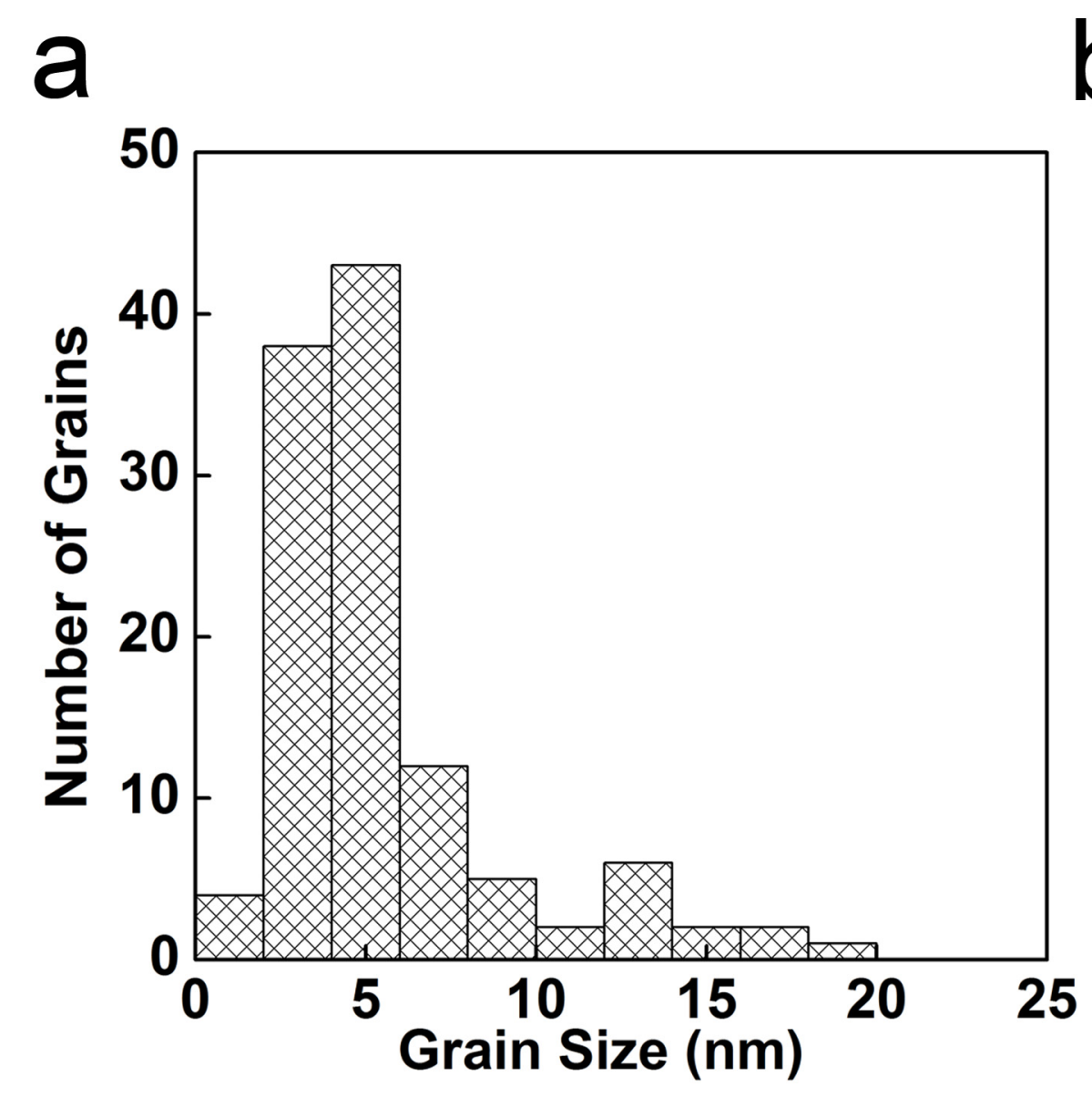

b

figure 8

C

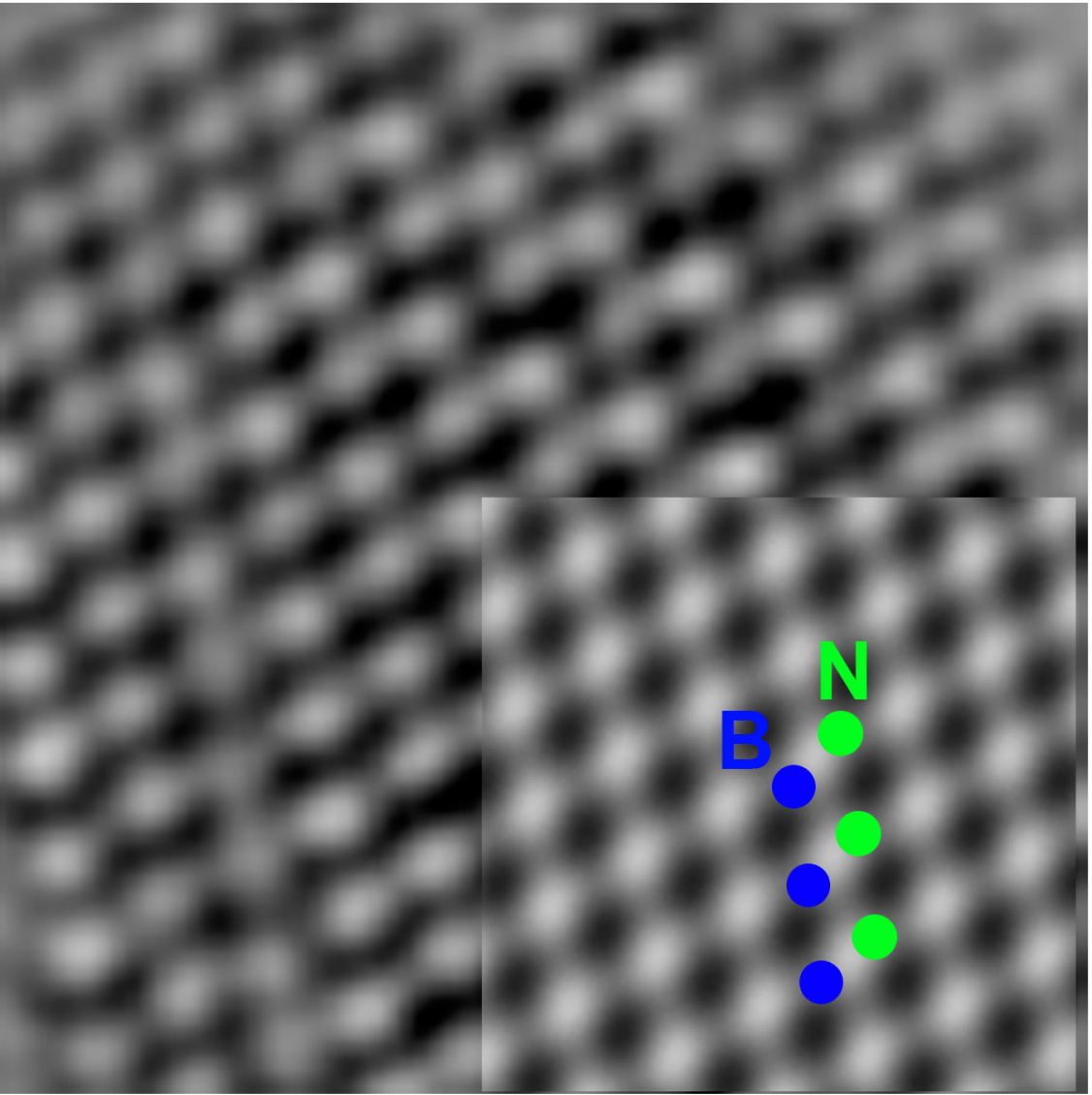

d
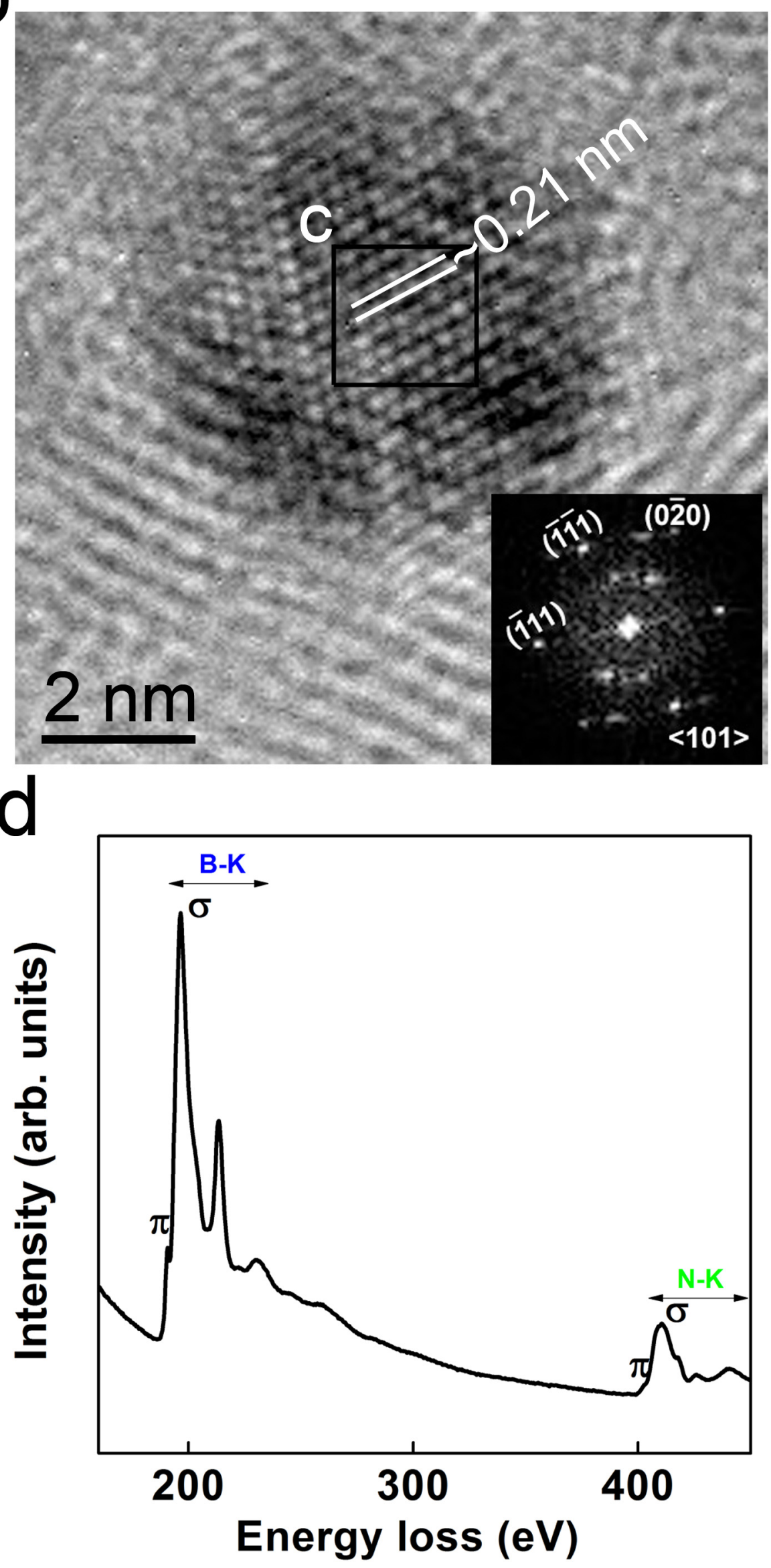
fig10

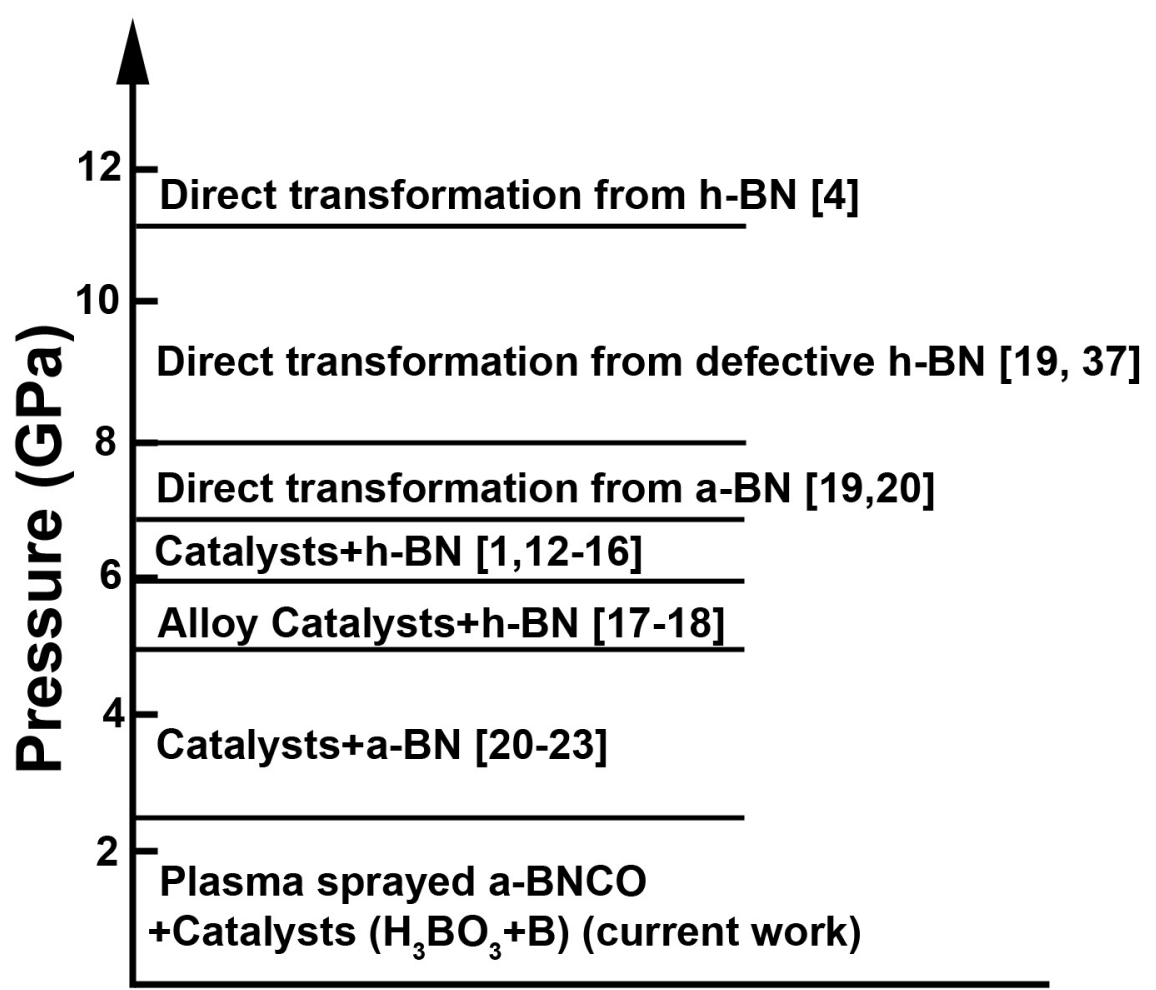

